Do UV-A radiation and blue light during growth prime leaves to cope with acute high-light in photoreceptor mutants of Arabidopsis thaliana?

\title{
Brelsford, Craig
}

2019-03

Brelsford, C , Morales Suarez, L O, Nezval , J , Kotilainen , T K, Hartikainen , S M , Aphalo , P J \& Robson , T M 2019 , ' Do UV-A radiation and blue light during growth prime leaves to cope with acute high-light in photoreceptor mutants of Arabidopsis thaliana? ' , Physiologia Plantarum, vol. 165 , no. 3 , pp. 537-554 . https://doi.org/10.1111/ppl.12749

http://hdl.handle.net/10138/307034

https://doi.org/10.1111/ppl.12749

unspecified

submittedVersion

Downloaded from Helda, University of Helsinki institutional repository.

This is an electronic reprint of the original article.

This reprint may differ from the original in pagination and typographic detail.

Please cite the original version. 

photoreceptor mutants of Arabidopsis thaliana?

4 Craig C. Brelsford ${ }^{1}$, Luis O. Morales ${ }^{1}$, Jakub Nezval' ${ }^{2}$, Titta K. Kotilainen ${ }^{1}$, Saara M. Hartikainen ${ }^{1}$, 5 Pedro J. Aphalo ${ }^{1}$ and T. Matthew Robson ${ }^{1 凶}$

6 Affiliations

$7{ }^{1}$ Organismal and Evolutionary Biology Research Programme, Viikki Plant Science Centre (ViPS),

8 Faculty of Biological and Environmental Sciences, 00014, University of Helsinki, Finland.

$9{ }^{2}$ Faculty of Science, University of Ostrava, 30. dubna 22, 70103 Ostrava, Czech Republic.

11 Correspondence email: matthew.robson@helsinki.fi

12

13

14 
Abstract (244/250 Words)

We studied how plants acclimated to growing conditions that included combinations of blue light and ultraviolet-A (UV-A) radiation, and whether their growing environment affected their photosynthetic capacity during and after a brief period of acute high light (as might happen during an under-canopy sunfleck). Arabidopsis thaliana wild-type Landsberg erecta (WT) were compared with mutants lacking functional blue-light-and-UV photoreceptors: phototropin 1 (phot1); cryptochromes (cry1 and cry2) and UV RESISTANT LOCUS 8 (uvr8). This was achieved using LED lamps in a controlled environment to create treatments with or without blue light, in a split-plot design with or without UV-A radiation. We compared the accumulation of phenolic compounds under growth conditions and after exposure to 30 minutes of high light at the end of the experiment ( 46 days), and likewise measured the operational efficiency of photosystem II ( $\varphi$ PSII a proxy for photosynthetic performance) and dark-adapted maximum quantum yield ( $F_{\mathrm{v}} / F_{\mathrm{m}}$ to assess PSII damage). Our results indicate that cryptochromes are the main photoreceptors regulating phenolic-compound accumulation in response to blue light and UV-A radiation, and a lack of functional cryptochromes impairs photosynthetic performance under high light. Our findings also reveal a role for UVR8 in accumulating flavonoids in response to a low UV-A dose. Interestingly, phototropin 1 partially-mediated constitutive accumulation of phenolic compounds in the absence of blue light. Low irradiance blue light and UV-A did not facilitate higher $\varphi$ PSII and $F_{\mathrm{v}} / F_{\mathrm{m}}$ to our acute high light treatment, however CRYs played an important role in ameliorating high-light stress.

Abbreviations

CHS, chalcone synthase ; cryl cry2, cryptochrome 1,2; $\phi$ PSII, Operating efficiency of photosystem II; $F_{\mathrm{v}} / F_{\mathrm{m}}$, Maximum quantum efficiency of PSII; BL, Blue light $-420-490 \mathrm{~nm} ; \mathrm{B}: \mathrm{G}$ - ratio of blue:green light defined as 420-490:500-570nm, HPLC-DAD, High performance liquid chromatography coupled with a diode array detector; PAR, Photosynthetically active radiation (400nm-700nm); phot 1, phototropin 1 mutant; PSII, Photosystem II; R:FR, Red : Far-red light ratio defined as 655-665:725-735m; SAS, Shade avoidance syndrome; UV, Ultraviolet radiation - 100-400nm; UV-A, Ultraviolet A radiation - 315400nm; UV-B, Ultraviolet B radiation - 280-315nm; uvr8-2, UV Resistance locus 8-2 mutant; WT, Landsberg erecta wild type; VPD, Vapour pressure deficit. 


\section{Introduction}

Plants experience a dynamic and heterogeneous light environment, where spectral composition and irradiance can change depending upon the time of day, and of year, as well as the surrounding vegetation (Constabel and Lieffers 1996, Montgomery and Chazdon 2001). To maintain a positive carbon balance, plants beneath canopies must respond to changes in solar radiation throughout the growing season (Augspurger 2003, Lopez et al. 2008, Dion et al. 2016). As well as reduced irradiance during spring due to canopy closure, differential attenuation of the blue (Casal 2013a; who define blue as $400-500 \mathrm{~nm}$ ) and UV-A regions affect spectral composition in the understorey (Grant et al. 2005). Spring bud burst of deciduous species in temperate and boreal forests results in a reduction in total under-canopy irradiance (Richardson and O'Keefe 2009) and a change in its spectral composition; reductions in the R:FR and blue:green ratios, and an increase in the UV:PAR ratio reaching the understorey (Flint and Caldwell 1998, Leuchner et al. 2011, Urban et al. 2012, Dengel et al. 2015). In response to increases in irradiance, plants produce phenolic compounds such as anthocyanins and phenolic acids (Agati et al. 2012). For instance, flavonoid glycosides can serve as sun-screens accumulating in the vacuoles, and bound to cell walls, of leaf epidermal cells protecting the mesophyll from photo-bleaching and photosynthetic damage (Jansen et al. 1998, Barnes et al. 2008). Flavonoids absorb UV radiation, whilst also functioning as antioxidants preventing damage from reactive oxygen species (Agati and Tattini, 2010). While the low UV irradiance under most canopies is unlikely to be harmful to plants, it might be exploited as a cue to optimise growth and defence to suit the environment (Mazza and Ballaré 2015).

Plants monitor their light environment through perception of specific regions of the spectrum, and coordinate a response that adjusts their growth strategy to suit the conditions (Casal 2013a, Casal 2013b). Different photoreceptors react to specific regions of the spectrum but often interact permitting the plant to be sensitive to complex changes in spectral irradiance (Heijde and Ulm, 2012). Plant photoreceptors cry1 and cry2, and phot 1 and phot2, primarily absorb photons in the blue and UV-A regions of the spectrum (Briggs and Huala 1999, Banerjee and Batschauer 2005). Of these, phot1 and phot2, are involved in stomatal opening, tropism and hypocotyl elongation responses (Casal 2000). Specifically, phot 1 promotes cryptochrome-mediated accumulation of anthocyanins in response to blue light (Kang et al. 2008), and phot 2 regulates the chloroplast-avoidance response to high light in angiosperms (Briggs and Christie 2002, Litthauer et al. 2015). To date, neither phot1 nor phot2 has been reported to regulate the pathways responsible for the accumulation of flavonoids. Photoreceptors, cry1 and cry2, alongside phyA and phyB detect the light cues which entrain the circadian clock (Somers et al. 1998). Hypocotyl elongation, seedling development, as well as the accumulation of flavonoids and anthocyanins are also regulated by cry1 and cry2 (Kubasek et al. 1992; Casal 2000, Shalitin et al. 2002). There is also evidence that cry1 
the SAS response (Ballaré et al. 1987, , Ballaré et al. 1990 Keller et al. 2011). Perception of UV-B through UVR8 attenuates the SAS by supressing stem elongation, in an antagonistic response to that triggered by phyB under FR (Mazza and Ballaré 2015). UVR8 also promotes the pathways for accumulation of flavonoids in response to UV-B radiation under controlled conditions (Kliebenstein et al. 2002) and at the solar UV-B irradiance occurring outdoors during July in Finland (Morales et al. 2013).

UV-B radiation has consistently been found to up-regulate the accumulation of flavonoids in plants, both in controlled experiments using UV-B lamps (Ballaré et al. 1995, Demkura \& Ballaré 2012), and in experiments conducted outdoors under solar UV-B radiation (Flint et al. 1985, Krizek et al. 1998, Morales et al. 2013). Although flavonoid accumulation in A. thaliana in response to UV-B has been well studied, less is known about the influence of the blue and UV-A regions of the spectrum on this response (Christie and Jenkins 1996, Fuglevand et al. 1996, Morales et al. 2013). UV-A radiation constitutes a greater proportion of the received solar irradiance than UV-B radiation, but is not attenuated by the ozone layer so has not been subject to such intensive research. There is evidence that some flavonoid groups are regulated mainly by UV-A and others predominately by UV-B (Kotilainen et al. 2008, Siipola et al. 2015, Verdaguer et al. 2017). For instance, in an outdoor experiment filtering out solar UV-A and UV-B, Kotilainen et al. (2008) found specific UV-A and UV-B effects on the accumulation of flavonols, flavones and cinnamic acids in Betula pendula and Alnus incana. Similarly, in an outdoor experiment filtering out different wavelengths of solar radiation, blue light had stronger effects than UV-A radiation on the accumulation of epidermal flavonol content in pea (Pisum sativum) (Siipola et al. 2015). Nevertheless, both UV-A radiation and blue light can elicit flavonoid-accumulation to varying degrees. Morales et al. (2013) suggested that the UV-A/blue light signalling pathway, most likely mediated by crys, maybe interacting with UVR8 to modulate UV-A responses such as flavonoid accumulation. However, there has been little research comparing the responses of plants to UV-A radiation with and without blue light, to examine whether these interactions between photoreceptor responses involve redundancy or fine-tuning between blue and UV-A radiation to regulate flavonoid accumulation.

Although PAR defines the spectral region of radiation useful for photosynthesis (McCree 1981),

105 beyond this region UV-A radiation has also been reported to increase the rate of photosynthesis in over

106100 plant species across a variety of life forms (Turnbull et al. 2013), including A. thaliana (Bilger et al.

107 2007). Chlorophylls (Chl) $a$ and $b$ can absorb radiation within the UV-A region (Lang and Lichtenthaler

108 1991, McCree 1981), supporting the suggestion that this region also has the potential to drive

109 photosynthesis. However, epidermal screening by UV-absorbing compounds such as flavonoids often

110 drastically reduces the amount of UV-A radiation reaching Chl $a$ and $\mathrm{Chl} b$ in the mesophyll (Bilger et al.

111 1997). This means that UV-A radiation may only be exploited as an alternative energy source for

112 photosynthesis in low light environments when plants have low concentrations of epidermal UV- 
113 absorbing compounds (Štroch et al. 2015).

114 UV-A radiation can have deleterious effects on photosynthesis (Jansen et al. 1998, Booij-James et

115 al. 2000). Both UV-A and UV-B radiation can cause damage to the PSII protein complex and reduce

116 quantum efficiency (Jansen et al. 1998); in doing so they increase photoinhibition of PSII more, per

117 photon, than excess PAR (Turcsányi and Vass 2000). However this effect is somewhat counterbalanced by

118 the fact that, UV-A radiation, as well as blue light, also enhance DNA-repair (Jansen et al. 1998, Booij-

119 James et al. 2000). Entrainment of the circadian rhythm of the photosynthetic capacity of PSII under low

120 or dynamic light conditions requires phot 1 and phot2, acting through mechanisms that are yet to be fully

121 elucidated (Litthauer et al. 2015). The role of phot 2 in the chloroplast avoidance response, permits

122 avoidance of high-light stress, allowing damage to PSII to be redistributed within the leaves (Davis and

123 Hangarter 2012). In response to blue light, CRY1 and CRY2 increase the expression of $p s b A$ and $p s b D$

124 (Thum et al. 2001, Tsunoyama et al. 2004, Onda et al. 2008). These genes promote the production of the

125 D1 and D2 proteins of PSII (Marder et al. 1987) which are needed to repair damage to PSII (Christopher

126 and Mullet 1994). Similarly, UVR8 can induce production of the D2 protein, though not D1 protein in

127 PSII, in response to UV-B radiation (Davey et al. 2012). However, little is known about the roles of

128 UVR8, CRYs and PHOTs in regulating the photosynthetic capacity of PSII in response to UV-A radiation.

129 We had three major aims in this experiment. Firstly, to test the respective roles of blue and UV-A

130 radiation in the accumulation of flavonoids in plants growing in a low-to-moderate light environment

131 (168 $\mu \mathrm{mol} \mathrm{m} \mathrm{m}^{-2} \mathrm{~s}^{-1}$ of PAR) and to identify those photoreceptors responsible for this response. Secondly, to

132 determine whether growth under these blue light and UV-A radiation treatments provided pre-emptive

133 acclimation to high-light (priming), and lastly whether flavonoid content was correlated with the

134 protection of PSII. To address these questions, we examined wild type (WT) Ler and mutants deficient in

135 UVR8, CRY1CRY2 and PHOT1 activity. We hypothesised that UVR8 would mediate an increase in

136 flavonoid accumulation and promote quantum efficiency of PSII in response to UV-A radiation through

137 increased photoprotection. We expected cryptochromes to increase leaf flavonoid content and promote the

138 quantum efficiency of PSII under blue light and UV-A radiation, and for this also to benefit PSII under

139 high-light exposure. Lastly, we considered that phot1 in plants growing under blue light and UV-A

140 radiation might promote cry-mediated anthocyanin accumulation and thus increase the overall phenolic

141 content.

142

143 Materials and Methods

144 Plant Material

145 All genotypes used in this experiment had the background accession Arabidopsis thaliana

146 Landsberg erecta. All seeds were produced simultaneously from plants grown under the same standard 
147 conditions in the growth rooms and greenhouses at the University of Helsinki, Viikki campus. The

148 following photoreceptor mutants were included in the experiments: phot1 (Inada et al. 2004), cryl cry2

149 (Mazzella et al. 2001), and uvr8-2 (Brown et al. 2005).

\section{Light treatments}

152 The experiment was set up in six individual compartments of equal size $(97 \mathrm{~cm}$ wide $\times 57 \mathrm{~cm}$ deep $\times 57$

$153 \mathrm{~cm}$ high) in a temperature-controlled room. These were arranged into three blocks, with each block

154 containing two compartments, each randomly allocated a light treatment (Blue Light / No Blue Light,

155 hereafter referred to as BL and no BL treatments). This meant that in total three of the six compartments

156 received a broad spectrum of irradiance from an array of LED lamps (Valoya AP67, 400-750nm, PAR 168

$157 \mu \mathrm{mol} \mathrm{m} \mathrm{s}^{-2}$ plus $32 \mu \mathrm{mol} \mathrm{m} \mathrm{m}^{-2} \mathrm{~s}^{-1}$ far red) and in the other three compartments blue light was attenuated by

158 wrapping film Rosco \#313 Canary Yellow (Westlighting, Helsinki, Finland) around the LED lamps (no

$159 \mathrm{BL}$ ): the height of lamps used in either treatment was adjusted to compensate for the lack of blue light and

160 equalise the PAR received across the treatments (SI Appendix 1 Fig. S1, Table S1). All compartments

161 were protected from extraneous light with white-black plastic film that blocked visible and UV radiation.

162 The number of layers of these plastic sheets was also adjusted to help equalise temperature across the 163 treatments (SI Appendix 1 Table S2). The UV-A treatment was applied as a split-plot factor by dividing 164 each of the six compartments in two halves with a curtain of Rosco \#226 film (Westlighting, Helsinki, 165 Finland) attenuating all UV-A radiation $(\lambda<400 \mathrm{~nm})$ : one half of each compartment received UV-A

166 radiation from high power LED arrays with peak emission at $365 \mathrm{~nm}$ (mean and SE of $15.0 \pm 0.6 \mu \mathrm{mol} \mathrm{m}^{-}$ $167{ }^{2} \mathrm{~s}^{-1}:$ Z1-Z1-10UV00, LED Engin, San Jose, CA, USA). Spectral irradiance measurements were made in 168 each compartment with an array spectroradiometer (Maya 2000Pro, Ocean Optics Inc., Dunedin, Florida, 169 USA). The BL and UV-A treatments were chosen to approximate the ratio of UV-A: BL and PAR 170 irradiance that we measured at noon in under-canopy shade in a Betula stand in southern Finland (Fig. 1, 171 example of under-canopy spectral irradiance, SI Appendix 1 Table S3 and Table S4). The broad-spectrum

172 lamps were kept on a 10-hour photoperiod from 08:00 to 18:00, whereas the UV-A LEDs were kept on for 173 a 4-hour period centred around 'noon' from 10:30 to 14:30, when UV-A irradiance is at its highest in 174 natural sunlight (Flint and Caldwell, 1998).

176 [Insert Fig. 1]

\section{Growing conditions}

179 Five seeds per 6-×-6 cm pot were sown directly into the growing substrate; well-soaked 1:1 pre180 fertilised peat to vermiculite (Agra-vermiculite; Pull Rhenen, TX Rhenen, the Netherlands) - a thin layer 
of peat was sieved at $2 \mathrm{~mm}$ gauge to provide a smooth surface giving good contact with the germinating seeds. After sowing, pots were placed for one day in darkness at $15^{\circ} \mathrm{C}$ to allow the seeds to become fully imbibed, then for three days the pots were under the light treatments at $5^{\circ} \mathrm{C}$-day $/ 2{ }^{\circ} \mathrm{C}$-night to facilitate cold stratification, before increasing to reasonable spring-time temperature for northern temperate latitudes of $15^{\circ} \mathrm{C}$ day $/ 10^{\circ} \mathrm{C}$ night $\left( \pm \mathrm{SE} 0.24^{\circ} \mathrm{C}\right)$, with a VPD of $0.17 \mathrm{kPa}$ day $/ 0.18 \mathrm{kPa}$ night during germination and subsequent growth. Temperature was continuously monitored with iButton sensors (Maxim Integrated, San Jose, United States) for the entire duration of the experiment to check that temperature was consistent among all compartments (SI Appendix 1 Table S2).

After germination when the first pair of true leaves became visible, the seedlings were thinned to one plant per pot, leaving 288 plants in the experiment: 6 plants $\times 5$ genotypes $\times 6$ compartments $\times 2$ split with or without UV-A radiation. The soil moisture was monitored daily, and maintained by adding $c 50 \mathrm{ml}$ per pot every 5-7 days. Plants were rotated within compartments to attenuate any unknown gradients in temperature, relative humidity, and irradiance.

\section{Acute high-light exposure}

Plants from each growth condition were randomly separated into two groups, a control group treatment. Each group contained 6 plants per treatment combination (genotype $\times$ blue $\times$ UV-A $\times$ highlight) divided in equal numbers per block.

High-light treatments were made in a temperature-controlled greenhouse compartment at $25^{\circ} \mathrm{C}$. The lamps (Osram Powerstar HQI-E 400W/D stadium lamps, Osram GmbH, Munich, Germany) warmed up for at least $1 \mathrm{hr}$ prior to implementing the treatment to ensure their emission was stable, and 75-mm deep baths of flowing water, placed between the lamps and plants, served as a heat sink reducing the warming effect of the lamps. Plants were kept underneath the lamps for exactly $30 \mathrm{~min}$, at which point the quantum yield of PSII was measured before they were returned to their growing conditions. Photon irradiance incident on the leaves of plants receiving the high-light treatment was $1800-2100 \mu \mathrm{mol}^{-1} \mathrm{~m}^{-2} \mathrm{~s}^{-1}$ PAR (SI Appendix 1 Figure S3, Table S5).

\section{Non-invasive measurements of UV-screening and leaf chlorophyll content}

A Dualex Scientific ${ }^{+}$device (Force-A ${ }^{\mathrm{TM}}$, Paris, France) was used to make non-destructive measurements of leaf pigments based on their optical properties. The leaf chlorophyll content is

212 calculated by the Dualex device based on the difference in transmission through the leaf in the near infra-

213 red at $710 \mathrm{~nm}$ and $850 \mathrm{~nm}$ (NIR), and in the red regions of the spectrum (Cerovic et al. 2012). The

214 relationship between leaf chlorophyll content $\left(\mu \mathrm{g} \mathrm{cm}^{-2}\right)$ and the chlorophyll-specific absorption index 
215 measured with the Dualex Scientific ${ }^{+}$was linear across the range of values we obtained (Robson et al.

216 unpublished data, Parry et al. 2014). The relative leaf adaxial-epidermal UV-A-absorbance at $375 \mathrm{~nm}$ is

217 calculated by the Dualex device based on chlorophyll fluorescence at $375 \mathrm{~nm}$ relative to chlorophyll

218 fluorescence in the red region of the spectrum while accounting for leaf chlorophyll content (Cerovic et

219 al. 2012). There is a linear relationship between this index of UV-absorbance at $375 \mathrm{~nm}$ and epidermal

220 flavonol content for the range of values that we report (Robson et al. unpublished data, also reviewed by

221 Julkunen-Tiitto et al. 2015).

222 Dualex measurements were made from all plants from both control and high-light groups, 45 days

223 after germination under the growing light conditions of the experiment between 15:30 and 18:00. A

224 second set of Dualex measurements were then taken three hours after the end of the high-light exposure

225 (day 46) back in the experimental compartments of the growth room. Both sets of measurements were

226 made on the same two fully-expanded mature non-senescent unshaded leaves per plant that were

227 horizontal to the light source at the point of measurement. Plants were all rosettes with no visible signs of

228 development beyond their vegetative state at the time of measurement.

\section{Measurements of the quantum yield of PSII}

Quantum yield at midday (day 45), of same two leaves per plant selected for Dualex measurements, was measured with a PAM fluorometer (mini-PAM, Heinz-Walz GmbH, Effeltrich, Germany). We used $\phi$ PSII (calculated as $F_{\mathrm{q}}{ }^{\prime} F_{\mathrm{m}}$; Murchie and Lawson, 2013) as an indicator of the operating efficiency of PSII during the day for plants under the light treatments (day 45). It was possible to compare the $F_{\mathrm{q}}{ }^{\prime} / F_{\mathrm{m}}{ }^{\text {' }}$ of leaves measured in ambient conditions under the light treatments since the photon irradiance was matched to be as similar as possible in each treatment combination. A second set of $F_{\mathrm{q}}{ }^{\prime} / F_{\mathrm{m}}$ ' measurements were made the following day (day 46) between 10:00 and 12:00 for the control group under growing light treatments (as before), and between 12:00 and 13:50 for the test group under high-light exposure. To assess damage to PSII, $F_{\mathrm{v}} / F_{\mathrm{m}}$ of all plants was measured from the same leaves as $\phi$ PSII measurements

\section{Quantitative Analysis of Soluble Phenolic Compounds}

\section{$243 \quad \underline{\text { HPLC Analysis }}$}

244 Directly following the Dualex measurements after the high-light exposure (day 46), the leaves used

245 for these optical assessments were harvested from both control and high-light plants. Only those leaves, or 246 parts of leaves, that were unshaded by other leaves in the rosette were selected for biochemical extraction 247 of soluble (i.e. non-cell-wall bound) phenolic compounds. Likewise, the petiole and proximal lamina 248 section were excluded ensuring that the sampled leaves had actually received their respective radiation 
treatments, following Julkunen-Tiitto et al. (2015). After each sample was harvested, they were weighed ensuring that there was at least $100 \mathrm{mg}$ fresh weight of each sample, and immediately frozen in liquid nitrogen inside $\mathrm{Al}$-foil packets and stored at $-80^{\circ} \mathrm{C}$. Samples were lyophilised in the dark and transported on dry ice for HPLC and UV/Vis analyses. Leaves were ground in 3-ml 40\% methanol using a pestle and mortar, before being placed in an ultrasonic bath (Ultrasonic compact cleaner UC 006 DM1, Tesla, CZ), and sonicated for $5 \mathrm{~min}$. The samples were then centrifuged for $3 \mathrm{~min}$ at $6000 \mathrm{RPM}$, equivalent of 3461 RCF (EBA 20 Hettich Zentrifugen, Germany). $1 \mathrm{ml}$ of supernatant was filtered through a $0.2 \mu \mathrm{m}$ filter (Premium Syringe Filters, Agilent, USA) and used for HPLC-DAD analysis with an Agilent 1200 HPLC system (Agilent Technologies, USA). Each extract for HPLC-DAD (1 ml) was collected in a vial, and 5 $\mu l$ of sample was injected into the HPLC for each analysis. Separation was performed using a Hypersil Gold (C18, 50 x $2.1 \mathrm{~mm}$ column, with $1.9 \mu \mathrm{m}$ particles, Thermofisher scientific, San Jose, CA, USA) chromatographic column which was tempered to $30{ }^{\circ} \mathrm{C}$ during the separation process. Two mobile phases were used, mobile phase A consisted of 5\% acetonitrile, and mobile phase B consisted of $80 \%$ acetonitrile, and both phases were acidified using methanoic acid with a ratio of 1:999 v/v. Flow of the mobile phases was $0.3 \mathrm{ml} \mathrm{min}{ }^{-1}$. Compounds were detected at 270, 314 and $360 \mathrm{~nm}$. For the purpose of quantification of phenolic compounds, and for particular flavonoids, peaks on an optical chromatogram detected at $360 \mathrm{~nm}$ were manually integrated. Peak areas were adjusted against the fresh weight of leaves and used to determined relative content of compounds in samples. The spectra of phenolic compounds were measured across a spectral interval of $190-750 \mathrm{~nm}$. The identification of compounds was done with an UltiMate 3000 HPLC system (Thermofisher Scientific, USA San Jose, CA) followed by Q-TOF mass spectrometer (micrOTOF-QII, Bruker Daltonics, Germany) by comparing the retention time order, UVVIS absorption spectra, and the mass per charge ratio of the mother and fragment ions of each phenolic compound against values from the literature (SI Appendix 2). The compound identity was subsequently assigned to individual peaks detected during quantitative HPLC-DAD analysis according to their retention time and UV-VIS absorption spectra similarity (SI Appendix 2).

\section{Data Analysis}

The effects of genotype, blue light, UV-A radiation, and high-light exposure and their interaction were tested using analysis of variance (ANOVA). All statistical tests were done in R version 3.2.2 (2016, The R Foundation for Statistical Computing, Vienna, Austria). Data were analysed using a linear mixedeffects model (LME), which was fitted using the NLME package (Pinheiro and Bates 2000). The function 'weights=varPower' was used to reduce heterogeneity of variance in the model. the split-plot factor, and genotype nested within the split-plot factor. At the end of the experiment, high 
light was also included in the model. There were three replicates of each treatment combination for each genotype, corresponding to the number of split-compartments receiving the same treatment.

The six compartments were divided into three blocks based on the arrangement of pairs of BL and no BL treatments. Block was used as a random factor in the model. Multiple comparisons were only tested when treatment effects were $p<0.05$ using a fit-contrast comparison to test for differences between each genotype and the WT. Holm's correction was used to adjust $p$ values for multiple testing. The R package ggplot2 (Wickham and Chang 2013) was used to construct all figures. Pearson's correlation was used to test the relationship of epidermal flavonoids with $\phi$ PSII and $F_{\mathrm{v}} / F_{\mathrm{m}}$, as well as leaf chlorophyll with $\phi$ PSII and $F_{\mathrm{v}} / F_{\mathrm{m}}$

\section{Results}

The accumulation of flavonoids is associated with CRYs under BL but both CRYs and UVR8 under UV-A radiation

Non-invasive measurements of UV-screening

Genotypes differed in their adaxial leaf flavonol content, as assessed by Dualex, $(p<0.001$, SI Appendix 1 Table S6A). Although the effect of BL was marginally non-significant overall $(p=0.062)$, there was a significant interactive effect of BL and genotype on UV-screening (Genotype $\times$ BL: $p<0.001$ ). Similarly, while UV-A had no significant effect overall $(p=0.217)$, there was a significant Genotype $\times$ UVA interaction $(p=0.006)$.

These interactions indicate that the response to each of BL and UV-A radiation differed among genotypes. BL significantly increased UV-screening in $u v r 8-2$, phot 1 and WT (respectively $p=0.022$, $p=0.034, p=0.020$; Fig. 2), but had no effect compared with no BL in cryl cry2 $(p=0.430)$. In the presence of BL, cryl cry 2 had the lowest epidermal flavonol contents of all the genotypes, and was $24.5 \%$ lower than WT ( $p<0.001$, Table 1, Fig. 2).

Considering those treatments without BL, epidermal flavonol content in the upper epidermis of phot 1 plants was lower than that of WT, in both treatments with and without UV-A radiation $(p=0.001$, $p=0.021$, respectively). In contrast, $u v r 8-2$ grown in the absence of both BL and UV-A, had higher leaf epidermal flavonol content than WT $(p=0.007)$, and cryl cry 2 was not significantly higher than WT ( $p=0.422$, Fig. 2). In the treatment receiving UV-A radiation but not BL, there was no significant difference in the epidermal flavonol content in either $u v r 8-2$ or cryl cry 2 compared to the WT $(p=0.290$, $p=0.934)$.

Growth under the UV-A radiation treatments caused a decrease in epidermal flavonol content

315 compared with no UV-A (irrespective of BL) in cryl cry2, and $u v r 8-2(p<0.002, p=0.022)$, and had no

316 effect on phot 1 or WT ( $p=0.931, p=0.256)$. After a $4 \mathrm{~h}$ period back in their growing conditions, the 30 
min of high-light exposure had caused no significant effect on the leaf adaxial epidermal anthocyanin or

318 flavonol content ( $p=0.895, p=0.305$ Fig. $2 \&$ SI Appendix 1 Fig. S3), but leaf chlorophyll content was $6.8 \%$ higher in plants exposed to high-light ( $p=0.026$, SI Appendix 1 Fig. S4).

[Insert Fig. 2]

Epidermal anthocyanin content followed the opposite trends to epidermal flavonol content in general, hence in plants with low epidermal flavonol content the epidermal anthocyanin content tended to be high, but a genotype-specific difference in this relationship was not detected (Table 1, SI Appendix 1 Figure S5). This pattern also meant that epidermal anthocyanin content was higher in the no BL than to the BL treatments, however the relative differences between genotypes and treatments were much smaller than for epidermal flavonol content (Table 1, Fig. 2). Leaf chlorophyll content tended to co-vary in the same direction as epidermal flavonoids among genotypes and light treatments (Table 1). All genotypes apart from crylcry2 had higher chlorophyll content in the BL treatment than the no BL treatment (Table 1), whereas the effect of UV-A radiation on chlorophyll content was non-significant (SI Appendix 1 Table S6B).

[Insert Table 1]

\section{Qualitative analysis of the effects of blue light and UV-A radiation on leaf phenolic compounds}

The same nine phenolic compounds were present in all our treatments at concentrations above the detection limits, allowing their quantification by HPLC-DAD (listed in Table 2). Of these nine compounds, four were confirmed to be kaempferol derivatives, three were sinapic-acid derivatives, and two could not be positively identified.

Genotype had a significant effect overall on the sum of all measured phenolic compounds per unit

343 effect overall on total phenolic content $(p=0.158, p=0.124)$, however, genotype and $\mathrm{BL}$ had a significant

344 interactive effect $(p=0.004)$ following a similar pattern in the direction and size of effects to the leaf

345 adaxial-epidermal flavonol content measured with the Dualex. BL significantly increased total phenolic

346 content in phot 1, compared with the no BL treatment ( $p=0.012$, Fig. 3, Table 2$)$, but had no significant

347 effect on any other genotypes (Table 2). Pairwise comparisons of genotypes revealed that in the BL only

348 cryl cry2 had significantly lower total phenolic content than WT $(p<0.001)$, but no other significant

349 differences between genotypes and WT (Fig. 3, SI Appendix 1 Table S7). High-light treatment had no

350 significant effect on the total phenolic content of leaves sampled $4 \mathrm{~h}$ after the exposure (SI Appendix 1 
Table S8A-K).

[Insert Fig. 3] weight was dependent on genotype, given that genotype had a significant effect overall $(p=0.001)$, and there was a significant interaction between genotype and BL ( $p=0.027$ : Table 2 ). However BL and UV-A radiation had no significant overall effect on kaempferol content $(p=0.161, p=0.094)$. Pairwise comparisons also showed that when cryl cry2 was grown under BL, it had $11.4 \%$ lower total kaempferol content than WT ( $p=0.040$ : Table 2$)$, but phot 1 and $u v r 8-2$ did not differ significantly from WT ( $p=0.097$, $p=0.453$ ). The accumulation of kaempferol derivatives appeared to be partly regulated by phot 1 in the absence of BL, as only phot 1 had a significantly lower kaempferol content than WT in the no BL; a difference of $12 \%$.

As with kaempferol derivatives, the concentration of the total sinapic-acid derivatives per unit fresh weight differed among genotypes $(p<0.001)$. BL had no significant effect overall on sinapic-acid content ( $p=0.154$ ), but this was because the genotypes responded in contrasting ways to BL (significant interactive effect; $p<0.001)$. UV-A radiation had no significant overall effect on sinapic-acid content $(p=0.210)$. Under the BL treatment, phot 1 mutants had a significantly higher total sinapic-acid content than without BL ( $p=0.023$ ), but the other genotypes did not differ (Table 2). Pairwise comparisons of sinapic-acid contents between the WT and the photoreceptor mutants, showed that under BL leaves of cry 1 cry 2 and phot 1 had a significantly lower content of sinapic-acid derivatives than those of WT $(p<0.001, p=0.012)$. In the no BL treatment, phot 1 had significantly lower sinapic-acid content than WT $(p=0.006)$, with all other genotypes showing no significant differences from WT (Table 2 ).

Among the individual phenolic compounds identified, genotype had a significant effect on the concentrations of sinapoyl glucose $(p<0.001)$, sinapoyl tartronate $(p<0.001)$, kaempferol 3-O-rha-glu 7-Orha $(p<0.001)$, kaempferol 3-O-glu-glu 7-O-rha $(p=0.002)$ and kaempferol 3-O-glu 7-O-rha $(p=0.014)$. The response of these compounds to UV-A, and the interaction between BL and genotype, were consistent in their direction and extent with the responses of the total content of phenolic compounds described above (Table 2, SI Appendix 1, Table S7). Although we report differences in the content of these various phenolic compounds among our treatments, as described above, we did not detect a change in the

\section{3 [Insert Table 2]}


Blue light increases the quantum yield of photosystem II via CRYs under growth conditions

To investigate the role of each class of photoreceptors in maintaining PSII function, we first measured $\phi$ PSII, and the maximum quantum yield $\left(F_{v} / F_{\mathrm{m}}\right)$ of dark-adapted plants, under their growing conditions to serve as a baseline to compare against $\phi$ PSII under high light and $F_{v} / F_{\mathrm{m}}$ after high-light exposure.

The $F_{v} / F_{\mathrm{m}}$ of dark-adapted plants under their growing conditions differed significantly with genotype ( $p=0.012)$ and BL ( $p=0.049)$, but not UV-A $(p=0.314)$. Genotypes differed in their response of $F_{v} / F_{\mathrm{m}}$ to $\mathrm{BL}$, producing a significant interaction between genotype and $\mathrm{BL}(p=0.036)$. BL significantly increased $F_{\mathrm{v}} / F_{\mathrm{m}}$ compared with no BL in WT and phot1 ( $\left.p=0.037, p=0.030\right)$, but had no significant effect on cryl cry2 nor $u v r 8-2(p=0.301, p=0.109)$. This result meant that cryl cry 2 had a significantly lower $F_{\mathrm{v}} / F_{\mathrm{m}}$ than WT under the BL treatment $(p<0.001)$, while the other genotypes were not significantly different from the WT (Fig. 4).

[Insert Fig. 4]

Genotype and BL also significantly affected $\phi$ PSII under growth conditions $(p<0.001, p=0.010$, Fig. 5); UV-A had no significant effect $(p=0.169)$. BL significantly increased $\phi$ PSII in phot $1, u v r 8-2$ and WT $(p=0.028, p=0.016, p=0.031)$, but had no significant effect on cryl cry2 $(p=0.215)$. In the $\mathrm{BL}$ treatment, cryl cry 2 had the lowest $\phi$ PSII of all genotypes $(p<0.001)$, but no other genotypes were significantly different from WT (Fig. 5). When grown in the absence of BL, phot 1 had significantly lower $\phi$ PSII in comparison to WT ( $p=0.001)$, however there were no other significant differences from the WT among genotypes in the no BL treatment (Table S9).

Under 30-min saturating high-light treatment, $\phi$ PSII was reduced, but also became more variable within genotypes and treatment combinations, compared with plants not receiving high light. This may partially explain why, although $\phi$ PSII under high light differed with genotype $(p<0.001)$, previous growth under BL or UV-A had no significant overall effect, nor interactive effects with genotype (Fig. 6; Table 1). Among genotypes, cryl cry 2 had the lowest $\phi$ PSII under high light and was the only mutant to significantly differ from the WT ( $p=0.007)$. The $F_{\mathrm{v}} / F_{\mathrm{m}}$ measured in dark-adapted leaves 4 hrs after the end 
of the acute high-light exposure was not significantly affected by genotype, BL nor UV-A (Fig. 7, $p=0.080, p=0.234, p=0.338$, respectively). Electron transport rate (ETR) and non-photochemical quenching (NPQ) were higher in all genotypes under the high-light exposure, but were not significantly different between genotypes or treatments (SI Appendix 1, Fig S17 and FigS18).

\section{Discussion}

426 Cryptochromes and UVR8 are both associated with photosynthetic-pigment accumulation in response to low UV-A radiation treatments during growth.

Our experiment examined how growth under broad spectrum irradiance treatments with and without BL and UV-A radiation affected photoprotection and flavonoid accumulation. Under these conditions, based on a ratio of UV-A:BL similar to that in understorey shade, BL had a relatively large effect compared with UV-A on leaf epidermal UV-screening by flavonoids. This flavonoid response to BL can be largely attributed to the role of cryptochromes. Within each genotype, the effects of BL and UV-A radiation on phenolic content quantified from leaf extracts were consistent with those for UV-epidermal screening by flavonols assessed optically, however among genotypes this relationship was not as consistent (Table 2, Figs. 2 \& 3). Considered together, the increase in optically-assessed flavonol content in plants grown under BL, as well as several phenolic compounds quantified from leaf extracts, can be attributed to the role of cryptochromes in promoting the accumulation of phenolic compounds in response to blue light.

Recent studies reporting large increases in the accumulation of phenolic compounds and flavonoids

443 caused by blue light have been conducted outdoors in experiments compared against attenuated solar blue 444 light (Siipola et al. 2015), or in controlled conditions using high irradiances of blue light, together with 445 PAR equivalent to full sunlight (Hoffman et al. 2015, Taulavuori et al. 2016). However, even with the 446 moderate PAR in our experiment, our BL treatment had a strong effect on phenolic accumulation which 447 outweighed that of our UV-A radiation treatment. From our results, we can assert that functional CRY1 448 and CRY2, promote photoprotective, as well as photomorphogenic responses to blue light

449 (Vandenbussche et al. 2005, Keller et al. 2011). Similarly, the small increase we report in chlorophyll 450 content in response to BL can also be attributed to the role of functional CRYs (Table 1). CRY 1 has been 451 reported to maintain a high concentration of chlorophyll in A. thaliana seedlings exposed to 24 hrs high 452 light (Kleine et al. 2007), and to increase chlorophyll concentration in the roots of A. thaliana in response 
453 to blue light (Usami et al. 2004). Surprisingly, our results are the first that we are aware of to find that

454 CRYs mediate an increase in chlorophyll content in the leaves of A. thaliana grown under blue light.

455 Although it has already been shown that phot1 promotes cry-mediated accumulation of

456 anthocyanins (Kang et al. 2008), hitherto there was no evidence that phot 1 elicits the accumulation of

457 flavonoids in the absence of blue light. Our result, that epidermal flavonol content was significantly lower

458 in phot 1 when BL was attenuated, suggests that phot 1 may contribute to the baseline accumulation of

459 flavonoids in the absence of (or at very low irradiances of) blue light. This does not necessarily imply that

460 phot1 itself promotes pathways that can mediate flavonoid accumulation, maybe phot1 simply affects the

461 metabolism of the plant in such a way that directs investment into the production of flavonoids. In this

462 respect, it would be interesting to know how phot interacts with other photoreceptors to regulate

463 constitutive flavonoid production.

464 We hypothesized that UV-A radiation would increase flavonol content in our WT plants based on

465 the results of previous solar UV-attenuation studies outdoors which differentially-attenuated UV-A

466 radiation from the spectrum (Ibdah et al. 2002 [attenuated $50 \%$ solar $<360 \mathrm{~nm}$ ], Kotilainen et al. 2008,

467 Kotilainen et al. 2009, Morales et al. 2013 [all three attenuated 50\% solar $<400 \mathrm{~nm}$ ]). However, our UV-A

468 treatment did not increase epidermal flavonol content assessed using Dualex. There are several possible

469 explanations for this discrepancy between our results and UV-A supplementation studies. We used a UV-A

470 LED source with a narrow peak at $365 \mathrm{~nm}$, whereas the majority of UV-A-supplementation studies which

471 have used UV-A fluorescent lamps with a broader spectrum across the UV-A region (Joshi et al. 2007

472 [330-390 nm], Victório et al. 2011 [320-400 nm], Štroch et al 2015 [350-400 nm]). The absorption spectra

473 of all the photoreceptors considered here, and additionally phytochrome, absorb in the UV-A region

474 (Shinomura et al. 1996, Briggs and Huala 1999, Heijde and Ulm, 2012). This potential for interactions

475 among photoreceptors may imply that responses elicited are highly wavelength dependent within the UV-

476 A region. Alternatively, it is possible that the plants acclimated to the low but ecologically-realistic UV-A

477 irradiance used in this experiment $\left(15 \mu \mathrm{mol} \mathrm{m} \mathrm{m}^{-2} \mathrm{~s}^{-1}\right.$ : Fig. 1, SI Appendix 1 Tables S1, S2, S3) throughout

478 their growth, or that it was not high enough to elicit a flavonoid response in WT. Transmittance to the

479 chloroplasts of non-damaging amounts of UV-A radiation may even be useful since it can drive

480 photosynthesis (Bilger et al. 2007, Turnbull et al. 2013, Štroch et al 2015), being absorbed by chlorophyll

481 and inducing chlorophyll fluorescence (McCree 1981, Lang and Lichtenthaler 1991). The potential

482 benefits of UV-A radiation for photosynthesis could be more pronounced in shaded understorey

483 conditions, where light is often limiting and the UV-A irradiance is considered unlikely to be high enough

484 to induce stress or photodamage (Štroch et al 2015 Casal 2013b) but is proportionally enriched compared

485 to PAR (Flint and Caldwell 1998, Leuchner et al. 2011, Urban et al. 2012, Dengel et al. 2015).

486 Although PHOT1 absorbs UV-A radiation, and has been shown to have an action spectrum for 
tropism in the UV-A region, our UV-A treatment did not affect either the epidermal flavonol content or leaf phenolic content of phot 1 mutants. It has previously been suggested that the flavonoid response to BL and UV-A radiation in $A$. thaliana is most likely to be largely driven by CRY1 and CRY2, which control CHS expression and the subsequent flavonoid biosynthesis (Jenkins et al. 2001). Our results provide evidence that cryptochromes and UVR8 (but not phototropin1) are both involved in eliciting flavonoids in response to UV-A radiation. Whilst UVR8 has an absorption tail to at least $315 \mathrm{~nm}$ (Christie et al. 2012), there is currently no evidence of absorption by UVR 8 as far as $365 \mathrm{~nm}$; the UV-A peak emitted by LEDs in our experiment. However, other studies have shown UVR8 to affect the accumulation of flavonoids in response to solar UV-A (Morales et al. 2013). An in-depth study of how far into the UV-A region UVR8 is able to coordinate responses would be of great interest.

It is possible that pleiotropic effects could contribute to the flavonoid response to BL and UV-A among the different genotypes used in our experiment e.g. the mutations could indirectly affect photosynthesis and other metabolic pathways that could also contribute to differences in plant physiology including flavonoids. However, for cryptochromes and UVR8 there is already some evidence from studies of gene expression, as well as transcripts and metabolites suggesting their regulation of flavonoids in response to BL and UV-A radiation (Wade et al. 2001, Morales et al. 2013), whereas such evidence is lacking for phot 1 .

Cryptochromes promote accumulation of soluble leaf phenolic compounds in response to both blue light and UV-A radiation, whereas UVR8 promotes accumulation of sinapoyl glucose in response to

\section{UV-A radiation}

The composition of phenolic compounds, as opposed the total phenolic content, is often reported to change in response to blue light and UV-A radiation (Morales et al. 2010, Morales et al. 2013, Siipola et al. 2015). A coherent change in composition would involve the conversion of kaempferols to quercetinderivatives which have higher ROS-scavenging activity, along with sinapic-acid derivatives such as

512 sinapate esters, which absorb more UV radiation in epidermal cells (Sheahan, 1996, Götz et al. 2010,

513 Agati et al. 2012, Csepregi et al. 2016). In contrast to this expectation, our treatments did not produce

514 detectable changes in the composition of kaempferol and sinapic-acid derivatives, only affecting their

515 content. The directional effects of BL and UV-A on leaf phenolic content were consistent with the changes

516 in epidermal flavonoid content (Figs. 2 \& 3), although to varying degrees of significance (SI Appendix 1

517 Table S6A, S7 and Tables S8A-K, Fig S15 and S16). Such a result is consistent with studies that report a

518 change in the total content of phenolic compounds in response to UV-A, as opposed to a change in their

519 composition (Maffei et al. 1999, Lee et al. 2014). Cryptochromes have been reported to mediate a general

520 increase in flavonoid accumulation in response to blue light (Ouzounis et al. 2015, Taulavuori et al. 2016), 
521 and blue light can have species-specific effects on the total concentration of phenolic-acid derivatives

522 (Ouzounis et al. 2015, Taulavuori et al. 2016). There has been to-date little evidence of a specific

523 contribution of cryptochromes to the accumulation of particular groups of phenolic compounds in

524 response to BL as well as to UV-A radiation. Here, we found that cryptochromes were associated with the

525 accumulation of total phenolic-acid derivatives, several individual sinapic-acid derivatives and

526 kaempferol derivatives in response to growth under BL, as well as the accumulation of sinapoyl glucose

527 and kaempferol 3-O-glu-glu-7-O-rha in response to growth under UV-A radiation.

528 In addition to cryptochromes, functional UVR8 promoted the accumulation of sinapoyl glucose as

529 well as epidermal flavonols in response to UV-A radiation. This result supports the suggestion by Morales

530 et al. (2013) that cryptochromes and UVR8 could modulate the accumulation of phenolic compounds in

531 the UV-A region. One potential reason for plants to have multiple photoreceptors whose absorption

532 spectra lie within the UV-A region is that coordination between crys and UVR8 could provide the optimal

533 composition of phenolic compounds for growth and defense in a dynamic light environment where the

534 ratio of UV radiation to blue light often differs from that of full sunshine (Fig. 1, SI Appendix 1 Table S3).

535 However, we are not yet in a position to identify the signalling mechanisms by which cryptochromes and

536 UVR8 could co-regulate the accumulation of phenolic compounds in general, nor the interconversion of

537 specific compounds from the phenolpropanoid pathway (Wade et al. 2001, Morales et al. 2013).

Moderate blue light but not UV-A radiation during growth enhances the operating efficiency and maximal quantum yield of PSII via cryptochromes

The UV-A treatment used in our experiment did not have any significant effect on the operating efficiency of PSII ( $\phi$ PSII) nor on the maximum quantum efficiency of PSII $\left(F_{\mathrm{v}} / F_{\mathrm{m}}\right)$. Similarly, a study

543 using higher UV-A irradiance on barley (Hordeum vulgare) found no significant effect on $F_{\mathrm{v}} / F_{\mathrm{m}}$ (Štroch et

544 al. 2015). However, under unshaded conditions solar UV-A radiation has been reported to decrease $F_{\mathrm{v}} / F_{\mathrm{m}}$

545 in the A. thaliana mutant $u v r 8-1$ (Coffey et al. 2017). Increases in $F_{\mathrm{v}} / F_{\mathrm{m}}$ for plants that have been

546 cultivated under blue light have been reported in many plant species (Goins et al. 1997, Matsuda et al.

547 2008, Terfa et al. 2013, Hoffmann et al. 2015), yet to our knowledge this is the first study of the effects of 548 blue light on $\phi$ PSII and $F_{\mathrm{v}} / F_{\mathrm{m}}$ to compare differences amongst $A$. thaliana photoreceptor mutants $c r y 1$ 549 cry2, phot 1 and $u v r 8-2$. Here, we report that CRYs mediated an increase of both $\phi$ PSII and $F_{\mathrm{v}} / F_{\mathrm{m}}$ during 550 growth under BL, and $\phi$ PSII when subjected to acute high light, suggesting that CRYs play an important 551 role in the induction of photoprotection. It is conceivable that such a mechanism would be useful for a 552 plant during the transition from shade to a sunfleck, which is accompanied by a particularly large shift in 553 blue light. It has been suggested that CRYs could affect leaf morphology in response to blue light in such 554 a way as to moderate the absorption of light passing through the leaf or alter the ratio of absorption 
between PSI and PSII reaction centres (Murchie and Lawson 2013, Miao et al. 2016). Mechanisms such as these may explain the small increase in $F_{\mathrm{v}} / F_{\mathrm{m}}$ and $\phi$ PSII induced by growth under BL in our experiment. CRYs mediate blue-light activation of D1 and D2 proteins, increasing the amount available for PSII repair (Thum et al. 2001, Tsunoyama et al. 2004, Onda et al. 2008), and so may also be integral to the normal functioning of PSII. Such mechanisms could explain the manner by which CRYs increased $\phi$ PSII and $F_{\mathrm{v}} / F_{\mathrm{m}}$ under BL during growth in our experiment.

Klem et al. (2015) found the quantum efficiency of PSII to be positively correlated with leaf flavonoid content in $H$. vulgare under high-light stress. However, in our study there was no overall relationship between $\phi$ PSII or $F_{\mathrm{v}} / F_{\mathrm{m}}$ and with either epidermal UV-screening by flavonoids (SI Appendix 1 Fig. S7- Fig. S10) or leaf chlorophyll content (Fig. S11- S14). These results seem to rule out flavonoids as being directly responsible for an improvement in photoprotection in our experiment. We did not measure the carotenoid content in our samples, however of the induction of carotenoids represents an alternative mechanism whereby plants can mitigate photoinhibition through NPQ (Horton et al. 1996, Li et al. 2000), and may explain those differences in $\phi$ PSII and $F_{\mathrm{v}} / F_{\mathrm{m}}$ among the genotypes that are not consistent with flavonoid accumulation. Boccalandro et al. (2012) reported a reduced photosynthetic capacity of cry 1 cry 2 mutants when exposed to high light suggesting that nonstomatal limitations could be responsible: one such limitation is a reduced electron transport rate per unit area (Boonman et al. 2009). Additionally, Kleine et al. (2007) have demonstrated that cry1 is necessary for the activation of 77 genes out of 996 that respond to high light, including the gene for Vitamin B6 which provides antioxidant activity against ROS stress. All of the above examples and our own results support the contribution of CRYs in initiating those high-light responses in plants, through which a higher $\phi$ PSII and $F_{\mathrm{v}} / F_{\mathrm{m}}$ can be maintained through mechanisms besides photoprotection endowed by flavonoids.

\section{Ecological implications of blue light and UV-A photoreceptor responses}

Whilst $A$. thaliana is not an understorey species, as a model plant it has provided insight as to how UVR8 and phytochromes coordinate shade responses (Fraser et al. 2016), as well as optimising flavonoid content beneath a patchy canopy (Mazza and Ballaré 2015). Under controlled conditions, we report important roles for cryptochromes and UVR8 in coordinating the accumulation of phenolic compounds in response to UV-A radiation and blue light at an irradiance that can be found in understorey shade. It remains to be seen whether naturally-occurring forest species would respond similarly to equivalent changes in these wavelength regions.

In our experiment, there was a larger effect of blue light increasing flavonoid accumulation than

587 that of UV-A radiation. Although the UV-B irradiance in understorey shade is very low, both UV-A and

588 UV-B radiation are enriched relative to PAR. There is evidence that the photoprotection endowed by 
flavonoids, especially against high irradiances of UV-B as well as UV-A radiation (Li et al. 1993, Jansen et al. 1998), could constitute a precautionary response to sunflecks by increasing antioxidant capacity (Gould et al.2000). Flavonoid responses to UV radiation are known to be dose dependent (reviewed by Robson et al. 2015). For instance, Morales et al. (2010) reported a dose-dependent response of certain flavonoids to UV-A radiation, which was quadratic under UV-B radiation. Considering the enrichment in UV-B radiation relative to PAR in understorey shade (Flint and Caldwell 1998), the effects of understorey UV-B radiation on flavonoid content and its synergistic effects with blue light would be worthy of investigation since they could be more pronounced than those of UV-A radiation.

The epidermal flavonol contents we report were within the range of published values for $A$.

598 thaliana exposed to solar radiation for $36 \mathrm{hrs}$ (Morales et al. 2013), but lower than the range of values

599 reported in H. vulgare exposed to solar radiation at a higher irradiance of supplemental UV-A than used in 600 our experiment (Klem et al. 2015). The relatively low values of epidermal UVA-absorption in our study 601 maybe one reason we did not find the same correlative relationship between flavonoid content and $\phi$ PSII 602 or $F_{\mathrm{v}} / F_{\mathrm{m}}$ as reported previously by Klem et al. (2015). Although equally, this could reflect species-specific 603 difference in this response for $H$. vulgare and A. thaliana, as further exemplified by the cultivar-specific 604 differences in Lactuca sativa (Ouzounis et al. 2015). These inconsistencies among species exemplify the need to study the ecological relevance of this response for understorey species, and the physiological mechanisms which allow plants to acclimate and capitalise on transient sunflecks between periods of shade in the understorey.

\section{Conclusions}

Cryptochromes and UVR8 both have regulatory effects on the flavonoid response to UV-A radiation in plants grown under controlled conditions, in light treatments based on a ratio of UV-A: BL

612 and PAR irradiance measured in understorey shade. Flavonol content in the adaxial epidermis did not

613 significantly correlate with $\phi$ PSII or $F_{\mathrm{v}} / F_{\mathrm{m}}$ values, nor did the UV-A radiation and BL treatments

614 noticeably prime leaves to cope with acute high-light. However, it is clear from our results that

615 cryptochromes are required for plants to attain high $\phi$ PSII and $F_{\mathrm{v}} / F_{\mathrm{m}}$ in the presence of blue light during

616 growth, and to maintain a high $\phi$ PSII under high-light exposure. The decreased tolerance to high light in

617 the cryl cry2 mutant (but not in the uvr8-2 mutant), with no concurrent decrease in epidermal flavonol

618 content, underlines the importance of cryptochromes in acclimation to high light through mechanisms

619 besides photoprotection by flavonoid accumulation.

\section{Author Contributions}

622 Craig Brelsford designed and carried out the experiment, analysed the data and wrote the 
623 manuscript. Luis Morales contributed to the writing of and ideas behind the manuscript. Jakub Nezval

624 carried out HPLC analysis, UV-Vis spectrophotometry and contributed to the writing of the manuscript.

625 Titta Kotilainen advised on the experimental design, spectral irradiance measurements, manuscript

626 writing and analysis. Saara Hartikainen helped design, set-up and the sampling of the experiment. Pedro

627 Aphalo helped to interpret the results and write the manuscript. T. Matthew Robson proposed the original

628 experiment, supervised the work and contributed throughout the entire process.

\section{Acknowledgements}

The Finnish Academy of Sciences funded this project through decisions \# 266523 and \# 304519 to

633 TMR. We thank Valoya Oy for providing the LED Lamps, David Israel, Neha Rai, Sari Siipola and Fang

634 Wang for advice on plant material and sampling, Gareth Jenkins and Tatsuya Kasai for initially donating

635 uvr8-2 and phot 1 seeds, and staff at Lammi Biological Station for their help with field measurements of

636 irradiance. The participation of JN was supported by the Czech Ministry of Education, Youth and Sports

637 Project LO1208 “TEWEP” National Feasibility Programme I and EU structural funding Operational

638 Programme Research and Development for Innovation project \# CZ.1.05/2.1.00/19.0388.

References

642 Augspurger CK (2003) Differences in leaf phenology between juvenile and adult trees in a temperate

643 deciduous forest. Tree Physiology 23

645 Agati G, Tattini M (2010) Multiple functional roles of flavonoids in photoprotection. New Phytologist 646 186: 786-793

648 Agati G, Azzarello E, Pollastri S, Tattini M (2012) Flavonoids as antioxidants in plants: location and 649 functional significance. Plant Science 196: 67-76

Ballaré CL, Sánchez RA, Scopel AL, Casal JJ, Ghersa CM (1987) Early detection of neighbour plants by 652 phytochrome perception of spectral changes in reflected sunlight. Plant, Cell \& Environment 10: 551-557

654 Ballaré CL, Scopel AL, Sánchez RA (1990) Far-red radiation reflected from adjacent leaves: an early 655 signal of competition in plant canopies. Science 247: 329-332 
Ballaré CL, Barnes PW, Flint SD (1995) Inhibition of hypocotyl elongation by ultraviolet-B radiation in

658 de-etiolating tomato seedlings. Physiologia Plantarum 93: 584-592

Banerjee R, Batschauer A (2005) Plant blue-light receptors. Planta 220: 498-502

Barnes PW, Flint SD, Slusser JR, Gao W, Ryel RJ (2008) Diurnal changes in epidermal UV transmittance of plants in naturally high UV environments. Physiologia plantarum 133: 363-372

Bilger W, Veit, M, Schreiber L, Schreiber U (1997). Measurement of leaf epidermal transmittance of UV radiation by chlorophyll fluorescence. Physiologia plantarum 101: 754-763

668 Bilger W, Rolland M, Nybakken, L (2007) UV screening in higher plants induced by low temperature in 669 the absence of UV-B radiation. Photochemical \& Photobiological Sciences 6: 190-195

Boccalandro HE, Giordano CV, Ploschuk EL, Piccoli PN, Bottini R, Casal JJ (2012). Phototropins but not cryptochromes mediate the blue light-specific promotion of stomatal conductance, while both enhance photosynthesis and transpiration under full sunlight. Plant physiology 158: 1475-1484

Booij-James IS, Dube SK, Jansen MA, Edelman M, Mattoo AK (2000) Ultraviolet-B radiation impacts light-mediated turnover of the photosystem II reaction center heterodimer in Arabidopsis mutants altered in phenolic metabolism. Plant Physiology: 1275-1284

Boonman A, Prinsen E, Voesenek LACJ, Pons TL (2009) Redundant roles of photoreceptors and cytokinins in regulating photosynthetic acclimation to canopy density. Journal of Experimental Botany 60: $1179-1190$

Briggs WR, Huala E (1999) Blue-light photoreceptors in higher plants. Annual review of cell and developmental biology 15: 33-62

Briggs WR, Christie, JM (2002) Phototropins 1 and 2: versatile plant blue-light receptors. Trends in Plant 687 Science, 7: 204-210

689 Brown BA, Cloix, C, Jiang GH, Kaiserli E, Herzyk P, Kliebenstein DJ, Jenkins GI (2005) A UV-B-

690 specific signaling component orchestrates plant UV protection. Proceedings of the National Academy of 
Casal JJ (2013a) Canopy light signals and crop yield in sickness and in health. ISRN Agronomy 2013

Casal JJ (2013b) Photoreceptor signaling networks in plant responses to shade. Annual review of plant biology 64: 403-427

Casal JJ (2000) Phytochromes, cryptochromes, phototropin: photoreceptor interactions in plants.

699 Photochemistry and Photobiology 71: 1-11

Cerovic ZG, Masdoumier G, Ghozlen NB, Latouche G (2012) A new optical leaf-clip meter for simultaneous non-destructive assessment of leaf chlorophyll and epidermal flavonoids. Physiologia plantarum 146: 251-260

Christie JM, Jenkins GI (1996) Distinct UV-B and UV-A/blue light signal transduction pathways induce chalcone synthase gene expression in Arabidopsis cells. The Plant Cell 8: 1555-1567

Christopher DA, Mullet JE (1994) Separate photosensory pathways co-regulate blue light/ultraviolet-Aactivated psbD-psbC transcription and light-induced D2 and CP43 degradation in barley (Hordeum vulgare) chloroplasts. Plant Physiology, 104: 1119-1129

712 Coffey A, Prinsen E, Jansen MAK, Conway J (2017) The UVB photoreceptor UVR8 mediates

713 accumulation of UV-absorbing pigments, but not changes in plant morphology, under outdoor conditions.

714 Plant, Cell \& Environment

716 Constabel AJ, Lieffers VJ (1996) Seasonal patterns of light transmission through boreal mixedwood

717 canopies. Canadian Journal of Forest Research 26: 1008-1014

719 Csepregi K, Neugart S, Schreiner M, Hideg É (2016) Comparative evaluation of total antioxidant 720 capacities of plant polyphenols. Molecules 21: 208

722 Davey MP, Susanti NI, Wargent, JJ, Findlay JE, Quick WP, Paul ND, Jenkins GI (2012) The UV-B 723 photoreceptor UVR8 promotes photosynthetic efficiency in Arabidopsis thaliana exposed to elevated 724 levels of UV-B.Photosynthesis research 114: 121-131 
726 Davis PA, Hangarter RP (2012) Chloroplast movement provides photoprotection to plants by

727 redistributing PSII damage within leaves. Photosynthesis research 112: 153-161

Dengel S, Grace J, MacArthur A (2015) Transmissivity of solar radiation within a Picea sitchensis stand under various sky conditions. Biogeosciences

Demkura PV, Ballaré CL (2012) UVR8 mediates UV-B-induced Arabidopsis defense responses against Botrytis cinerea by controlling sinapate accumulation. Molecular plant 5: 642-652

Dion PP, Brisson J, Fontaine B, Lapointe L (2016) Light acclimation strategies change from summer green to spring ephemeral as wild-leek plants age. American journal of botany 103: 963-970

Flint SD, Jordan PW, Caldwell MM (1985) Plant protective response to enhanced UV - B radiation under field conditions: leaf optical properties and photosynthesis. Photochemistry and Photobiology: 41: 95-99.

Flint SD, Caldwell MM (1998) Solar UV-B and visible radiation in tropical forest gaps: measurements

742 partitioning direct and diffuse radiation. Global change biology 4: 863-870

744 Fraser DP, Hayes S, Franklin KA (2016) Photoreceptor crosstalk in shade avoidance. Current opinion in 745 plant biology 33:1-7

Fuglevand G, Jackson JA, Jenkins GI (1996) UV-B, UV-A, and blue light signal transduction pathways

748 interact synergistically to regulate chalcone synthase gene expression in Arabidopsis. The Plant Cell 8:

$749 \quad 2347-2357$

Goins GD, Yorio NC, Sanwo MM, Brown CS (1997) Photomorphogenesis, photosynthesis, and seed

752 yield of wheat plants grown under red light-emitting diodes (LEDs) with and without supplemental blue

753 lighting. J Exp Bot 48: 1407-1413

755 Gould KS, Markham KR, Smith RH, Goris JJ (2000) Functional role of anthocyanins in the leaves of

756 Quintinia serrata A. Cunn. Journal of Experimental Botany 5: 1107-1115

758 Götz M, Albert A, Stich S, Heller W, Scherb H, Krins A, Langebartels C, Seidlitz HK and Ernst D (2010) 
PAR modulation of the UV-dependent levels of flavonoid metabolites in Arabidopsis thaliana (L.) Heynh. leaf rosettes: cumulative effects after a whole vegetative growth period. Protoplasma 243: 95-103

Grant RH, Apostol K, Gao W (2005) Biologically effective UV-B exposures of an oak-hickory forest understory during leaf-out. Agricultural and forest meteorology 132: 28-43

Heijde M, Ulm R (2012) UV-B photoreceptor-mediated signalling in plants. Trends in plant science 17:

$$
230-237
$$

Hoffmann AM, Noga G, Hunsche M (2015) High blue light improves acclimation and photosynthetic recovery of pepper plants exposed to UV stress. Environmental and Experimental Botany 109: 254-263

Horton P, Ruban AV, Walters RG (1996) Regulation of light harvesting in green plants. Annual review of plant biology 47: 655-684

Ibdah M, Krins A, Seidlitz HK, Heller W, Strack D, Vogt T (2002) Spectral dependence of flavonol and betacyanin accumulation in Mesembryanthemum crystallinum under enhanced ultraviolet radiation. Plant, Cell \& Environment 25: 1145-1154

Inada S, Ohgishi M, Mayama T, Okada K, Sakai T (2004) RPT2 is a signal transducer involved in phototropic response and stomatal opening by association with phototropin 1 in Arabidopsis thaliana. The Plant Cell 16: 887-896

Jansen MAK, Gaba V, Greenberg BM (1998) Higher plants and UV-B radiation: balancing damage, repair and acclimation. Trends in plant science 3: 131-135

Jenkins GI, Long JC, Wade HK, Shenton MR, Bibikova TN (2001) UV and blue light signalling: pathways regulating chalcone synthase gene expression in Arabidopsis. New Phytologist 151: 121-131

789 Partial protection of photosynthetic apparatus from UV-B-induced damage by UV-A radiation.

790 Environmental and experimental botany 59: 166-172

792 Julkunen-Tiitto R, Nenadis N, Neugart S, Robson TM, Agati G, Vepsäläinen J, Zipoli G, Nybakken L, 
793 Winkler B, Jansen MAK (2015) Assessing the response of plant flavonoids to UV radiation: an overview

794 of appropriate techniques. Phytochemistry reviews 14: 273-297

Kang B, Grancher N, Koyffmann V, Lardemer D, Burney S, \& Ahmad, M (2008) Multiple interactions between cryptochrome and phototropin blue-light signalling pathways in Arabidopsis thaliana. Planta 227: 1091-1099

800 Keller MM., Jaillais Y, Pedmale UV, Moreno JE, Chory J, Ballaré CL (2011). Cryptochrome 1 and 801 phytochrome B control shade-avoidance responses in Arabidopsis via partially independent hormonal 802 cascades. The Plant Journal 67:195-207

Kleine T, Kindgren P, Benedict C, Hendrickson L, Strand Å (2007) Genome-wide gene expression analysis reveals a critical role for CRYPTOCHROME1 in the response of Arabidopsis to high irradiance. Plant Physiology 144: 1391-1406

Klem K, Holub P, Štroch M, Nezval J, Špunda V, Tř́iska J, Jansen MA, Robson TM, Urban O (2015) Ultraviolet and photosynthetically active radiation can both induce photoprotective capacity allowing barley to overcome high radiation stress. Plant Physiology and Biochemistry 93: 74-83.

812 Kliebenstein DJ, Lim JE, Landry LG, Last RL (2002) Arabidopsis UVR8 regulates ultraviolet-B signal

813 transduction and tolerance and contains sequence similarity to human regulator of chromatin

814 condensation 1. Plant Physiology 130: 234-243

Kotilainen T, Tegelberg R, Julkunen-Tiitto R, Lindfors A, Aphalo PJ (2008) Metabolite specific effects of solar UV-A and UV-B on alder and birch leaf phenolics. Global change biology 14: 1294-1304

820 (2009) Assessment of UV biological spectral weighting functions for phenolic metabolites and growth

821 responses in silver birch seedlings. Photochemistry and photobiology 85: 1346-1355

823 Kubasek WL, Shirley BW, McKillop A, Goodman HM, Briggs W, Ausubel FM (1992) Regulation of

824 flavonoid biosynthetic genes in germinating Arabidopsis seedlings. The Plant Cell 4: 1229-1236

825 Lang M and Lichtenthaler HK (1991) Changes in the blue-green and red fluorescence-emission spectra of 826 beech leaves during the autumnal chlorophyll breakdown. Journal of plant physiology 138: 550-553 
828 Lee MJ, Son JE, Oh MM (2014) Growth and phenolic compounds of Lactuca sativa L. grown in a closed-

829 type plant production system with UV-A,-B, or-C lamp. Journal of the Science of Food and Agriculture

830 94: 197-204

832 Leuchner M, Hertel C, Menzel A (2011) Spatial variability of photosynthetically active radiation in

833 European beech and Norway spruce. Agricultural and forest meteorology 151: 1226-1232

835 Li J, Ou-Lee TM, Raba R, Amundson RG, Last RL (1993) Arabidopsis flavonoid mutants are

836 hypersensitive to UV-B irradiation. The Plant Cell Online 5: 171-179

838 Li XP, BjoÈrkman O, Shih C, Grossman AR, Rosenquist M, Jansson S, Niyogi KK (2000) A pigment-

839 binding protein essential for regulation of photosynthetic light harvesting. Nature 403: 391.

Litthauer S, Battle MW, Lawson T, Jones MA (2015) Phototropins maintain robust circadian oscillation of PSII operating efficiency under blue light. The Plant Journal 83: 1034-1045

844 Lopez OR, Farris-Lopez K, Montgomery RA, Givnish TJ (2008) Leaf phenology in relation to canopy

845 closure in southern Appalachian trees. American Journal of Botany 95: 1395-1407

847 Maffei M, Canova D, Bertea CM, Scannerini S (1999) UV-A effects on photomorphogenesis and 848 essential-oil composition in Mentha piperita. Journal of Photochemistry and Photobiology B: Biology 52:

$849 \quad 105-110$

Marder JB, Chapman DJ, Telfer A, Nixon PJ, Barber J (1987) Identification of psbA and psbD gene products, D1 and D2, as reaction centre proteins of photosystem 2. Plant molecular biology, 9: 325-333

854 Martínez-García JF, Gallemí M, Molina-Contreras MJ, Llorente B, Bevilaqua MRR, and Quail PH (2014)

855 The shade avoidance syndrome in Arabidopsis: the antagonistic role of phytochrome A and B

856 differentiates vegetation proximity and canopy shade. PloS one 9: e109275

858 Matsuda R, Ohashi-Kaneko K, Fujiwara K, Kurata K (2008) Effects of blue light deficiency on 859 acclimation of light energy partitioning in PSII and CO2 assimilation capacity to high irradiance in 860 spinach leaves. Plant and Cell Physiology 49: 664-670 
862 Mazza CA, Ballaré CL (2015) Photoreceptors UVR8 and phytochrome B cooperate to optimize plant

863 growth and defense in patchy canopies. New Phytologist 207: 4-9

Mazzella MA, Cerdán PD, Staneloni RJ, Casal JJ (2001) Hierarchical coupling of phytochromes and cryptochromes reconciles stability and light modulation of Arabidopsis development. Development 128: 2291-2299

McCree KJ (1981) Photosynthetically active radiation. - In Encyclopedia of Plant Physiology, Physiological Plant Ecology I. Responses to the Physical Environments (Lange OL,Nobel PS,Osmond CB, Ziegler H eds),Vol. 12: 41-55. Springer-Verlag, Berlin . ISBN 3-540-10763-0

Miao YX, Wang XZ, Gao LH, Chen QY, Mei QU (2016) Blue light is more essential than red light for maintaining the activities of photosystem II and I and photosynthetic electron transport capacity in cucumber leaves. Journal of Integrative Agriculture, 15: 87-100

Montgomery RA, Chazdon, RL (2001) Forest structure, canopy architecture, and light transmittance in tropical wet forests.Ecology 82: 2707-2718

Morales LO, Tegelberg R, Brosché M, Keinänen M, Lindfors A, Aphalo PJ (2010) Effects of solar UV-A and UV-B radiation on gene expression and phenolic accumulation in Betula pendula leaves. Tree Physiology 30: 923-934

Morales LO, Brosché M, Vainonen J, Jenkins GI, Wargent JJ, Sipari Nina, Strid Å, Lindfors AV, Tegelberg R,Aphalo PJ (2013) Multiple roles for UV RESISTANCE LOCUS8 in regulating gene expression and metabolite accumulation in Arabidopsis under solar ultraviolet radiation. Plant Physiology 161: 744-759

Murchie EH, Lawson T (2013) Chlorophyll fluorescence analysis: a guide to good practice and understanding some new applications. Journal of experimental botany, 64: 3983-3998

892 Neff MM, Chory J (1998) Genetic interactions between phytochrome A, phytochrome B and 893 cryptochrome 1 during Arabidopsis development. Plant Physiol 118: 27-35* 

transcripts in mature leaves: differential roles of cryptochrome 1 and cryptochrome 2 and dual function of SIG5 in the recognition of plastid promoters. The Plant Journal 55: 968-978

Ouzounis T, Parjikolaei BR, Fretté X, Rosenqvist E, Ottosen C (2015) Predawn and high intensity application of supplemental blue light decreases the quantum yield of PSII and enhances the amount of phenolic acids, flavonoids, and pigments in Lactuca sativa. Frontiers in plant science 6

Pinheiro JC, Bates DM (2000) Mixed-Effects Models in S and S-Plus. Springer New York. 528

R Development Core Team (2006) R: A Language and Environment for Statistical Computing. R

Foundation for Statistical Computing, Vienna, Austria

Richardson AD, O’Keefe J (2009) Phenological differences between understory and overstory. In

911 Robson T, Klem, K, Urban O, Jansen MA (2015) Re - interpreting plant morphological responses to

912 UV - B radiation. Plant, cell \& environment 38: 856-866

914 Shalitin D, Hongyun Y, Todd CM, Maskit M (2002) Regulation of Arabidopsis cryptochrome 2 by blue-

915 light dependent phosphorylation. Nature 417: 763

Sheahan JJ (1996) Sinapate esters provide greater UV-B attenuation than flavonoids in Arabidopsis thaliana (Brassicaceae). American Journal of Botany 679-686

Shinomura T, Nagatani A, Hanzawa H, Kubota M, Watanabe M, Furuya M (1996) Action spectra for phytochrome A-and B-specific photoinduction of seed germination in Arabidopsis thaliana. Proceedings of the National Academy of Sciences 93: 8129-8133

924 Siipola SM, Kotilainen T, Sipari N, Morales LO, Lindfors AV, Robson TM, Aphalo PJ (2015) Epidermal 925 UV-A absorbance and whole-leaf flavonoid composition in pea respond more to solar blue light than to 926 solar UV radiation. Plant, cell \& environment 38: 941-952

928 Somers DE, Devlin PF, Kay SA (1998) Phytochromes and cryptochromes in the entrainment of the 
932 A radiation during acclimation of the photosynthetic apparatus to UV-B treatment. Plant Physiology and

933 Biochemistry 96: 96

935 Taulavuori K, Hyöky V, Oksanen J, Taulavuori E, Julkunen-Tiitto R (2016) Species-specific differences in 936 synthesis of flavonoids and phenolic acids under increasing periods of enhanced blue light.

937 Environmental and Experimental Botany 121 (2016): 145-150

Terfa MT, Solhaug KA, Gislerød HR, Olsen JE, Torre S (2013) A high proportion of blue light increases

940 the photosynthesis capacity and leaf formation rate of Rosa $\times$ hybrida but does not affect time to flower

941 opening. Physiologia plantarum 148: 146-159

942

943 Turcsányi E, Vass I (2000) Inhibition of photosynthetic electron transport by UV-A radiation targets the

944 photosystem II complex. Photochemistry and Photobiology 72: 513-520

946 Thum KE, Kim M, Christopher DA, Mullet JE (2001) Cryptochrome 1, cryptochrome 2, and

947 phytochrome A co-activate the chloroplast psbD blue light-responsive promoter. The Plant Cell 13: 2747-

$948 \quad 2760$

950 Turnbull TL, Barlow AM, Adams MA (2013) Photosynthetic benefits of ultraviolet-A to Pimelea

951 ligustrina, a woody shrub of sub-alpine Australia. Oecologia 173: 375-385

953 Tsunoyama Y, Yoko I, Kazuya M, Maki K, Yoichi N, Go T, Yoshinori T, Takashi (2004) Blue light-

954 induced transcription of plastid-encoded psbD gene is mediated by a nuclear-encoded transcription

955 initiation factor, AtSig5. Proceedings of the National Academy of Sciences of the United States of

956 America, 101: 3304-3309

958 Urban O, Klem K, Ač A, Havránková K, Holišová P, Navratil M, Zitová M, Kozlová K, Pokorný R, 959 Šprtová M, Tomášková I (2012) Impact of clear and cloudy sky conditions on the vertical distribution of 960 photosynthetic CO2 uptake within a spruce canopy. Functional Ecology 26: 46-55

962 Usami T, Mochizuki N, Kondo M, Nishimura M, Nagatani A (2004) Cryptochromes and phytochromes 
963 synergistically regulate Arabidopsis root greening under blue light. Plant and Cell Physiology 45: 1798-

9641808.

965

966 Vandenbussche F, Pierik R, Millenaar FF, Voesenek LA, Van Der Straeten D (2005) Reaching out of the

967 shade. Current opinion in plant biology 8: 462-468

968

969 Verdaguer, D., Jansen, M. A., Llorens, L., Morales, L. O., \& Neugart, S. (2017). UV-A radiation effects on

970 higher plants: Exploring the known unknown. Plant Science 255: 72-81.

971

972 Victório CP, Leal-Costa MV, Schwartz Tavares E, Machado Kuster R, Salgueiro Lage, CL (2011) Effects

973 of supplemental UV-A on the development, anatomy and metabolite production of Phyllanthus tenellus

974 cultured in vitro. Photochemistry and Photobiology 87: 685-689

975

976 Wade HK, Bibikova TN, Valentine WJ, Jenkins GI (2001) Interactions within a network of phytochrome,

977 cryptochrome and UV-B phototransduction pathways regulate chalcone synthase gene expression in

978 Arabidopsis leaf tissue. The Plant Journal 25: 675-685

979

980 Wang H, Gu M, Cui J, Shi K, Zhou Y, Yu J (2009) Effects of light quality on $\mathrm{CO}_{2}$ assimilation,

981 chlorophyll-fluorescence quenching, expression of Calvin cycle genes and carbohydrate accumulation in

982 Cucumis sativus. Journal of Photochemistry and Photobiology B: Biology 96: 30-37

983

984 Wickham H, Chang W (2013) An implementation of the Grammar of Graphics. Version: 0.9.3.1 
Table 1. Chlorophyll content, upper epidermal anthocyanin content, and absorption at $375 \mathrm{~nm}$ detected spectrophotometrically for different $A$. thaliana genotypes grown under Blue Light (BL) / No Blue Light (No BL) treatments in a split-plot with UV-A, or without UV-A radiation. Chlorophyll and anthocyanin content measured with Dualex. Mean \pm 1 standard error.

Table 2. The concentration of total phenolic compounds, total kaempferol derivatives, total sinapic-acid derivatives, sinapoyl glucose, sinapoyl tartronate, kaempferol 3-O-rha-glu-7-O-rha, kaempferol 3-O-gluglu-7-O-rha, kaempferol 3-O-glu 7-O-rha, sinapoyl malate and kaempferol 3-O-rhamnoside 7-Orhamnoside. Means ( $\pm 1 \mathrm{SE}$ ) are displayed for four A. thaliana genotypes grown under Blue Light (BL)/ No Blue Light (No BL) treatments in a split-plot with UV-A, or without UV-A radiation. Measurements were taken on day 46 after germination. The content of phenolic compounds is given as the integrated peak area per $\mathrm{FW} \mathrm{mg}{ }^{-1}$. Mean \pm 1 standard error.

Fig. 1. Spectral photon irradiance on $4^{\text {th }}$ June 2016 at solar noon in the understorey of a Betula stand at Lammi Biological Station, Finland (130 masl, 61 $\left.03^{\prime} 14.3^{\prime \prime} \mathrm{N} 25^{\circ} 02^{\prime} 14.2^{\prime \prime E}\right)$. Irradiance measured in a sunfleck (solid line) is compared with shade caused by canopy foliage (dashed line).

Fig. 2. Epidermal flavonol content estimated through epidermal UV-absorbance at $375 \mathrm{~nm}$ with Dualex. Means ( $\pm 1 \mathrm{SE}$ ) are displayed for four A. thaliana genotypes grown under Blue Light (BL) / No Blue Light (No BL) treatments in a split-plot with UV-A $(\Delta)$ or without UV-A ( $)$ ) radiation.

Fig. 3. Integrated area of the sum of total phenolic compounds per fresh weight in mg. Means ( $\pm 1 \mathrm{SE})$ are displayed for four $A$. thaliana genotypes grown under Blue Light (BL) / No Blue Light (No BL) treatments in a split-plot with UV-A $(\Delta)$ or without UV-A $(\circ)$ radiation. Measurements were taken on day 46 after germination.

1015 Fig. 4. Maximum quantum yield of PSII $\left(F_{\mathrm{v}} / F_{\mathrm{m}}\right)$ measured in dark-adapted leaves. Means $( \pm 1 \mathrm{SE})$ are 1016 displayed for four A. thaliana genotypes grown under Blue Light (BL) / No Blue Light (No BL)

1017 treatments in a split-plot with UV-A $(\Delta)$ or without UV-A ( $\odot)$ radiation. Measurements were taken under 1018 growth conditions. 
1021 genotypes grown under Blue Light (BL) / No Blue Light (No BL) treatments in a split-plot with UV-A ( $\Delta$ )

1022 or without UV-A ( $)$ ) radiation. Measurements were taken under growth conditions.

1023

1024 Fig. 6. Operating efficiency of PSII measured as $\phi$ PSII. Means ( \pm 1 SE) are displayed for four A. thaliana 1025 genotypes grown under Blue Light (BL) / No Blue Light (No BL) treatments in a split-plot with UV-A ( $\Delta$ ) 1026 or without UV-A ( $)$ ) radiation. Measurements were taken under high-light conditions.

1028 Fig. 7. Maximum quantum yield of PSII $\left(F_{\mathrm{v}} / F_{\mathrm{m}}\right)$ measured in dark-adapted leaves. Means $( \pm 1 \mathrm{SE})$ are 1029 displayed for four A. thaliana genotypes grown under Blue Light (BL) / No Blue Light (No BL)

1030 treatments in a split-plot with UV-A $(\Delta)$ or without UV-A $(\circ)$ radiation. Measurements were taken after 1031 high-light conditions.

1032

1033 Fig. 8. A schematic representing the effects of low to moderate irradiance of blue light and UV-A radiation 1034 on the accumulation of epidermal flavonoids, and the effect of blue light and high light treatments on the 1035 maximal quantum efficiency $(\mathrm{Fv} / \mathrm{Fm})$ and operational efficiency of PSII ( $\phi$ PSII) represented by the image 1036 of PSII. Both cryptochromes and UVR8 contribute to the accumulation of epidermal flavonoids in response 1037 to UV-A, whereas in response to blue light, cryptochromes enhance the accumulation of epidermal 1038 flavonoids.

1039 
Table 1

\begin{tabular}{|c|c|c|c|c|c|c|c|c|c|c|c|}
\hline \multirow{2}{*}{$\begin{array}{l}\text { Genotype } \\
\text { phot1 }\end{array}$} & \multirow{2}{*}{$\begin{array}{l}\text { LED } \\
\mathrm{BL}\end{array}$} & \multirow{2}{*}{$\frac{\text { UV-A }}{\text { No UV-A }}$} & \multicolumn{3}{|c|}{$\begin{array}{l}\text { UV/Vis Absorption } \\
\text { Spectrophotometry }\end{array}$} & \multicolumn{3}{|c|}{ Chlorophyll Content } & \multicolumn{3}{|c|}{ Anthocyanin Content } \\
\hline & & & 17.22 & \pm & 1.02 & 19.94 & \pm & 0.01 & 0.180 & \pm & 0.003 \\
\hline cry1 cry2 & $B \mathrm{~L}$ & No UV-A & 18.21 & \pm & 1.25 & 24.25 & \pm & 0.01 & 0.185 & \pm & 0.004 \\
\hline uvr8-2 & $B L$ & No UV-A & 21.97 & \pm & 1.48 & 22.85 & \pm & 0.01 & 0.187 & \pm & 0.003 \\
\hline WT & $B L$ & No UV-A & 20.48 & \pm & 1.60 & 25.19 & \pm & 0.01 & 0.175 & \pm & 0.003 \\
\hline phot1 & $B \mathrm{~L}$ & UV-A & 16.83 & \pm & 1.89 & 18.15 & \pm & 0.02 & 0.180 & & 0.004 \\
\hline cry1 cry2 & $B L$ & UV-A & 15.35 & \pm & 2.27 & 24.23 & \pm & 0.01 & 0.198 & \pm & 0.004 \\
\hline uvr8-2 & $\mathrm{BL}$ & UV-A & 15.32 & \pm & 2.03 & 24.71 & \pm & 0.01 & 0.174 & \pm & 0.003 \\
\hline WT & $B \mathrm{~L}$ & UV-A & 19.99 & \pm & 2.61 & 23.94 & \pm & 0.01 & 0.173 & \pm & 0.003 \\
\hline phot1 & No $B L$ & No UV-A & 10.84 & \pm & 1.45 & 19.45 & \pm & 0.01 & 0.194 & \pm & 0.004 \\
\hline cry1 cry2 & No $B L$ & No UV-A & 14.84 & \pm & 1.17 & 16.62 & \pm & 0.01 & 0.196 & \pm & 0.005 \\
\hline uvr8-2 & No BL & No UV-A & 19.13 & \pm & 1.89 & 20.41 & \pm & 0.01 & 0.198 & \pm & 0.005 \\
\hline WT & No BL & No UV-A & 14.62 & \pm & 0.85 & 20.44 & \pm & 0.01 & 0.191 & \pm & 0.003 \\
\hline phot1 & No BL & UV-A & 9.22 & \pm & 1.03 & 18.18 & \pm & 0.01 & 0.198 & \pm & 0.005 \\
\hline cry1 cry2 & No BL & UV-A & 12.48 & \pm & 1.30 & 17.85 & \pm & 0.01 & 0.205 & \pm & 0.007 \\
\hline uvr8-2 & No $B L$ & UV-A & 14.23 & \pm & 0.80 & 19.72 & \pm & 0.01 & 0.192 & \pm & 0.004 \\
\hline WT & No BL & UV-A & 13.40 & \pm & 0.89 & 20.74 & \pm & 0.01 & 0.189 & \pm & 0.003 \\
\hline
\end{tabular}

1042

1043 
Table 2

\begin{tabular}{|c|c|c|c|c|c|c|c|c|c|c|c|c|c|c|c|c|c|c|c|c|c|c|c|c|c|c|c|c|c|c|c|c|}
\hline \multirow{2}{*}{$\begin{array}{l}\text { LED } \\
\text { Fullspec }\end{array}$} & \multirow{2}{*}{$\begin{array}{l}\text { UVA } \\
\text { NoUVA }\end{array}$} & \multirow{2}{*}{$\begin{array}{l}\text { Genotype } \\
\text { phot1 }\end{array}$} & \multicolumn{3}{|c|}{$\begin{array}{l}\text { total phenolic } \\
\text { compounds }\end{array}$} & \multicolumn{3}{|c|}{ total kaempferols } & \multicolumn{3}{|c|}{ total phenolic acids } & \multicolumn{3}{|c|}{ sinapoyl glucose } & \multicolumn{3}{|c|}{$\begin{array}{c}\text { sinapoyl } \\
\text { tartronate }\end{array}$} & \multicolumn{3}{|c|}{$\begin{array}{l}\text { kaempferol 3-O- } \\
\text { rha-glu-7-O-rha }\end{array}$} & \multicolumn{3}{|c|}{$\begin{array}{l}\text { kaempferol 3-O- } \\
\text { glu-glu-7-O-rha }\end{array}$} & \multicolumn{3}{|c|}{$\begin{array}{c}\text { kaempferol 3-O- } \\
\text { glu 7-O-rha }\end{array}$} & \multicolumn{3}{|c|}{ sinapoyl malate } & \multicolumn{3}{|c|}{$\begin{array}{l}\text { Kaempferol 3-O- } \\
\text { rhamnoside 7-O- } \\
\text { rhamnoside }\end{array}$} \\
\hline & & & 52.72 & \pm & 5.04 & 25.96 & \pm & 2.40 & 17.35 & \pm & 0.94 & 5.88 & \pm & 0.45 & 5.91 & \pm & 0.46 & 5.64 & \pm & 0.25 & 6.44 & \pm & 0.58 & 6.50 & \pm & 0.60 & 6.95 & \pm & 0.70 & 6.34 & \pm & 0.76 \\
\hline Fullspec & NoUVA & cry1 cry2 & 54.91 & \pm & 1.98 & 24.02 & \pm & 0.90 & 18.62 & \pm & 0.66 & 6.18 & \pm & 0.32 & 6.29 & \pm & 0.29 & 6.23 & \pm & 0.30 & 6.12 & \pm & 0.22 & 5.98 & \pm & 0.23 & 6.15 & \pm & 0.33 & 5.67 & \pm & 0.36 \\
\hline Fullspec & NoUVA & uvr8-2 & 64.73 & \pm & 4.24 & 28.91 & \pm & 1.86 & 21.35 & \pm & 1.43 & 7.28 & \pm & 0.51 & 7.19 & \pm & 0.50 & 6.90 & \pm & 0.39 & 7.16 & \pm & 0.47 & 9.79 & \pm & 0.48 & 6.87 & \pm & 0.43 & 7.21 & \pm & 0.43 \\
\hline Fullspec & NoUVA & WT & 61.61 & \pm & 3.55 & 26.81 & \pm & 1.33 & 20.88 & \pm & 1.34 & 7.21 & \pm & 0.55 & 7.24 & \pm & 0.54 & 7.09 & \pm & 0.49 & 6.77 & \pm & 0.39 & 6.67 & \pm & 0.35 & 6.43 & \pm & 0.32 & 6.28 & \pm & 0.23 \\
\hline Fullspec & UVA & phot1 & 40.74 & \pm & 5.58 & 20.10 & \pm & 2.35 & 14.85 & \pm & 1.95 & 4.87 & \pm & 0.76 & 4.79 & \pm & 0.71 & 4.88 & \pm & 0.69 & 5.04 & \pm & 0.63 & 5.04 & \pm & 0.59 & 5.19 & \pm & 0.52 & 5.14 & \pm & 0.48 \\
\hline Fullspec & UVA & cry 1 cry 2 & 50.96 & \pm & 3.50 & 22.48 & \pm & 3.28 & 17.17 & \pm & 1.20 & 5.69 & \pm & 0.54 & 5.74 & \pm & 0.51 & 6.59 & \pm & 1.01 & 5.67 & \pm & 0.38 & 6.31 & \pm & 0.81 & 6.28 & \pm & 0.69 & 6.11 & \pm & 0.79 \\
\hline Fullspec & UVA & uvr8-2 & 58.23 & \pm & 6.85 & 26.25 & \pm & 3.09 & 19.07 & \pm & 2.24 & 6.19 & \pm & 0.72 & 6.22 & \pm & 0.73 & 6.33 & \pm & 0.72 & 6.48 & \pm & 0.76 & 6.70 & \pm & 0.79 & 6.65 & \pm & 0.86 & 6.13 & \pm & 0.86 \\
\hline Fullspec & UVA & WT & 59.49 & \pm & 8.00 & 25.69 & \pm & 3.69 & 20.36 & \pm & 2.63 & 7.23 & \pm & 0.84 & 7.08 & \pm & 0.80 & 6.91 & \pm & 0.84 & 6.50 & \pm & 0.89 & 8.08 & \pm & 0.88 & 6.05 & \pm & 1.00 & 5.94 & \pm & 1.23 \\
\hline NoBlue & NoUVA & phot1 & 47.52 & \pm & 3.37 & 21.18 & \pm & 1.43 & 15.86 & \pm & 1.21 & 5.19 & \pm & 0.45 & 5.14 & \pm & 0.44 & 5.20 & \pm & 0.41 & 5.32 & \pm & 0.38 & 5.33 & \pm & 0.37 & 5.53 & \pm & 0.45 & 5.34 & \pm & 0.39 \\
\hline NoBlue & NoUVA & cry 1 cry 2 & 39.17 & \pm & 5.50 & 15.85 & \pm & 3.07 & 12.58 & \pm & 1.56 & 3.52 & \pm & 0.35 & 3.74 & \pm & 0.37 & 3.91 & \pm & 0.38 & 4.52 & \pm & 0.63 & 4.66 & \pm & 0.73 & 5.33 & \pm & 1.07 & 3.83 & \pm & 0.83 \\
\hline NoBlue & NoUVA & uvr8-2 & 49.41 & \pm & 5.03 & 21.31 & \pm & 2.07 & 16.72 & \pm & 1.76 & 6.19 & \pm & 0.69 & 6.09 & \pm & 0.67 & 5.90 & \pm & 0.64 & 5.35 & \pm & 0.56 & 5.27 & \pm & 0.56 & 4.44 & \pm & 0.41 & 5.11 & \pm & 0.44 \\
\hline NoBlue & NoUVA & WT & 48.27 & \pm & 13.20 & 21.84 & \pm & 2.15 & 15.84 & \pm & 1.40 & 5.14 & \pm & 0.42 & 5.17 & \pm & 0.43 & 5.16 & \pm & 1.85 & 5.33 & \pm & 0.49 & 6.66 & \pm & 0.53 & 6.19 & \pm & 0.80 & 6.29 & \pm & 0.69 \\
\hline NoBlue & UVA & phot1 & 40.15 & \pm & 3.79 & 18.29 & \pm & 1.73 & 13.32 & \pm & 1.35 & 4.04 & \pm & 0.51 & 4.18 & \pm & 0.49 & 4.39 & \pm & 0.46 & 4.52 & \pm & 0.41 & 4.50 & \pm & 0.45 & 5.10 & \pm & 0.66 & 4.74 & \pm & 0.56 \\
\hline NoBlue & UVA & cry1 cry2 & 31.66 & \pm & 2.97 & 13.46 & \pm & 4.31 & 9.52 & \pm & 1.02 & 3.45 & \pm & 0.31 & 3.70 & \pm & 0.31 & 3.30 & \pm & 0.22 & 3.34 & \pm & 0.33 & 4.37 & \pm & 0.31 & 3.73 & \pm & 0.32 & 3.73 & \pm & 1.95 \\
\hline NoBlue & UVA & uvr8-2 & 40.13 & \pm & 2.35 & 17.31 & \pm & 1.09 & 13.67 & \pm & 0.75 & 4.89 & \pm & 0.27 & 4.77 & \pm & 0.27 & 4.73 & \pm & 0.28 & 4.37 & \pm & 0.28 & 4.31 & \pm & 0.29 & 3.94 & \pm & 0.24 & 3.91 & \pm & 0.28 \\
\hline NoBlue & UVA & WT & 38.01 & \pm & 3.25 & 16.74 & \pm & 1.65 & 12.77 & \pm & 0.99 & 4.36 & \pm & 0.34 & 4.32 & \pm & 0.33 & 4.24 & \pm & 0.35 & 4.20 & \pm & 0.38 & 4.18 & \pm & 0.40 & 4.09 & \pm & 0.48 & 4.13 & \pm & 0.65 \\
\hline
\end{tabular}


Fig. 1

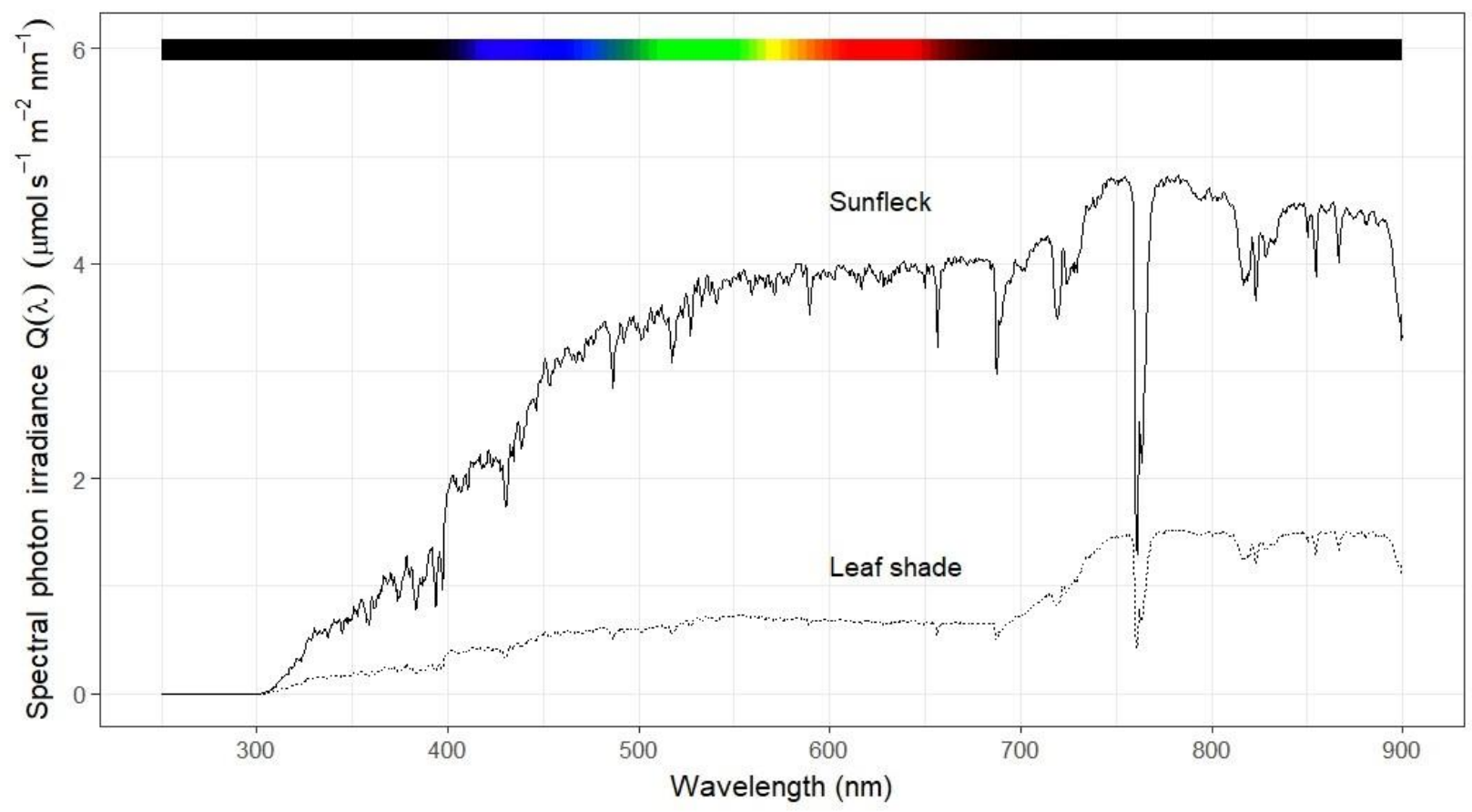

1051

1052 
1053 Fig. 2
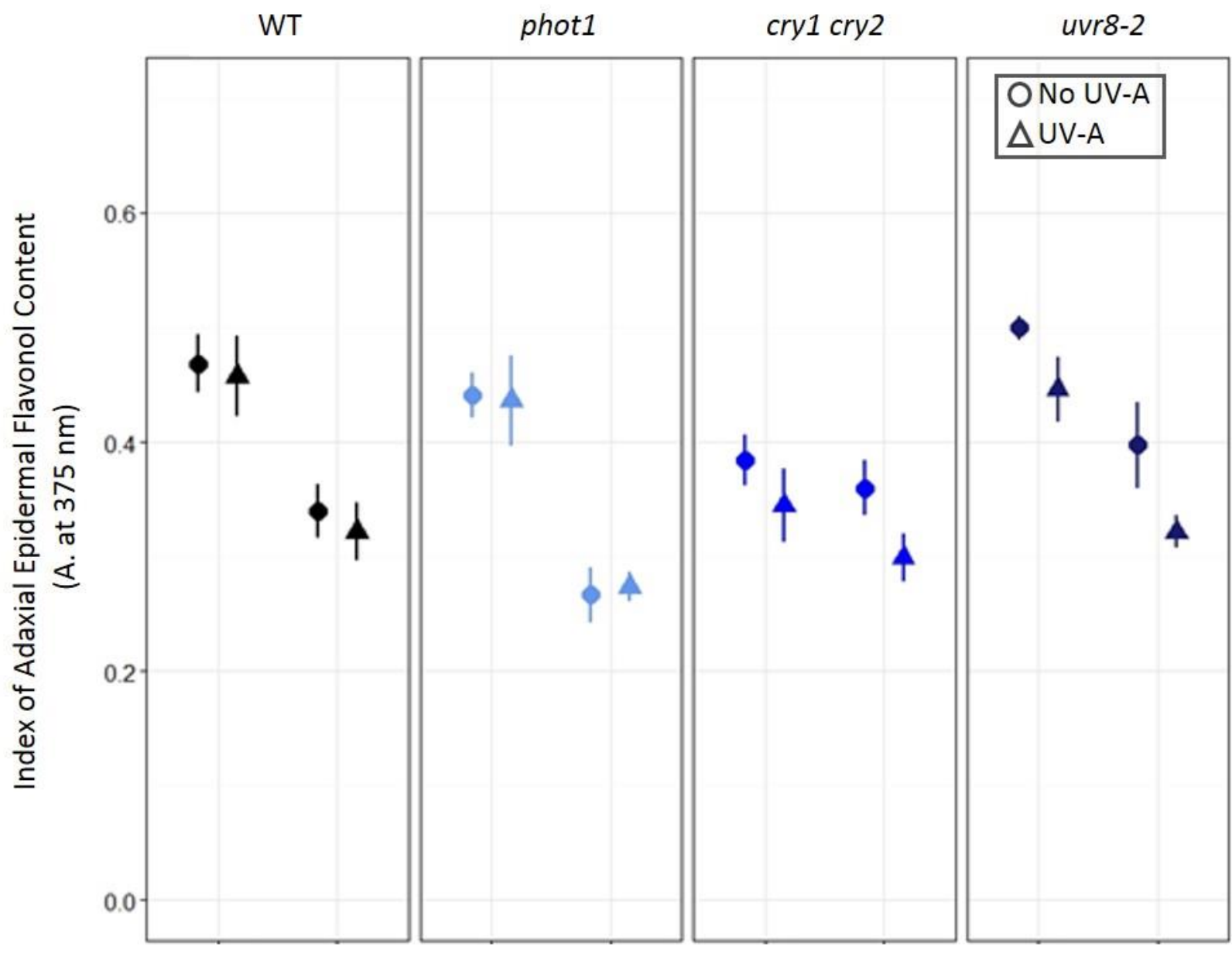

BL No BL

BL No BL

BL No BL

BL No BL

1054

Growth Under Blue-Light / No-Blue-Light Treatment

1055

1056 
1057 Fig. 3

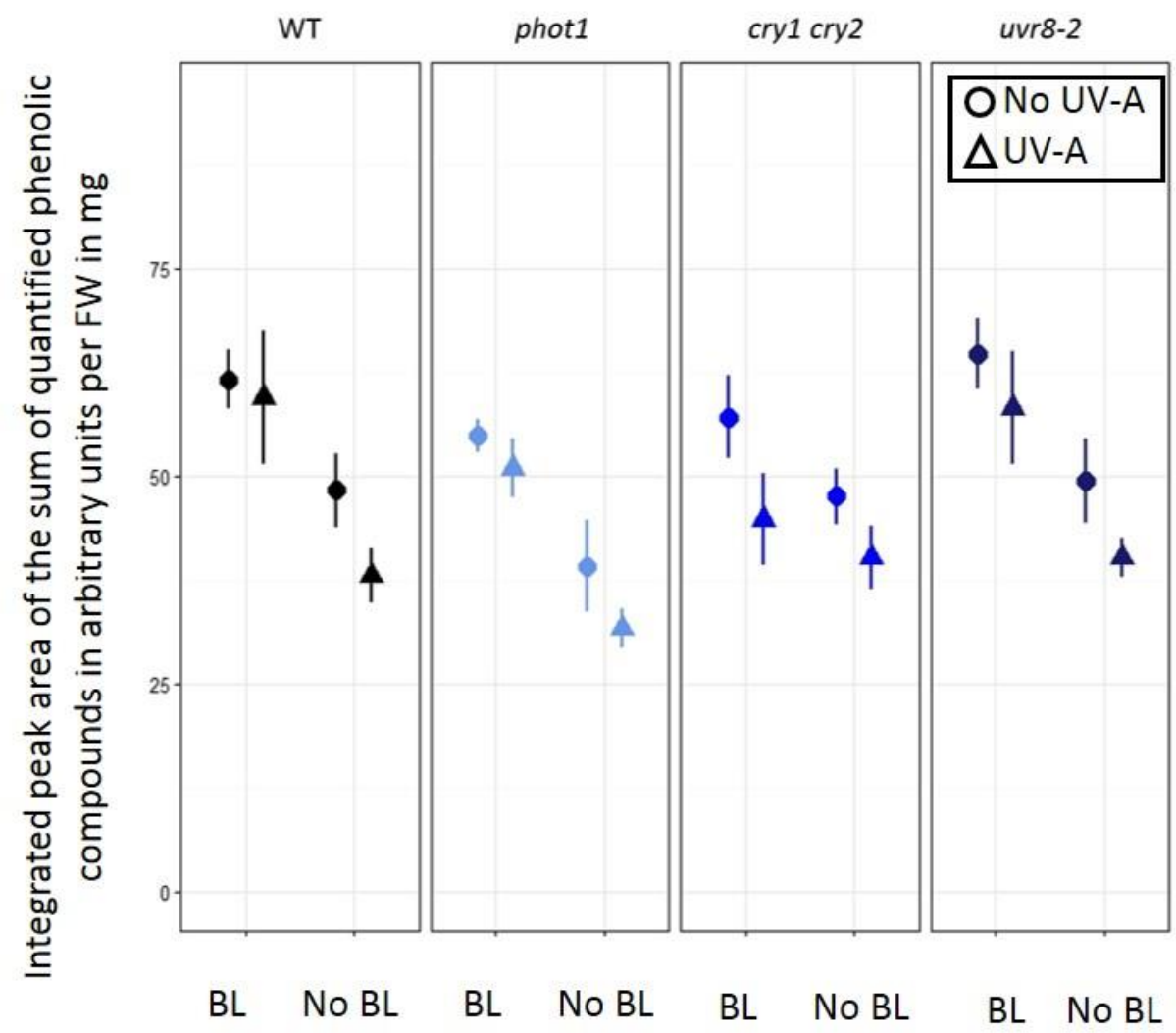

Growth Under Blue-Light / No-Blue-Light Treatment

1058

1059

1060 
1061 Fig. 4

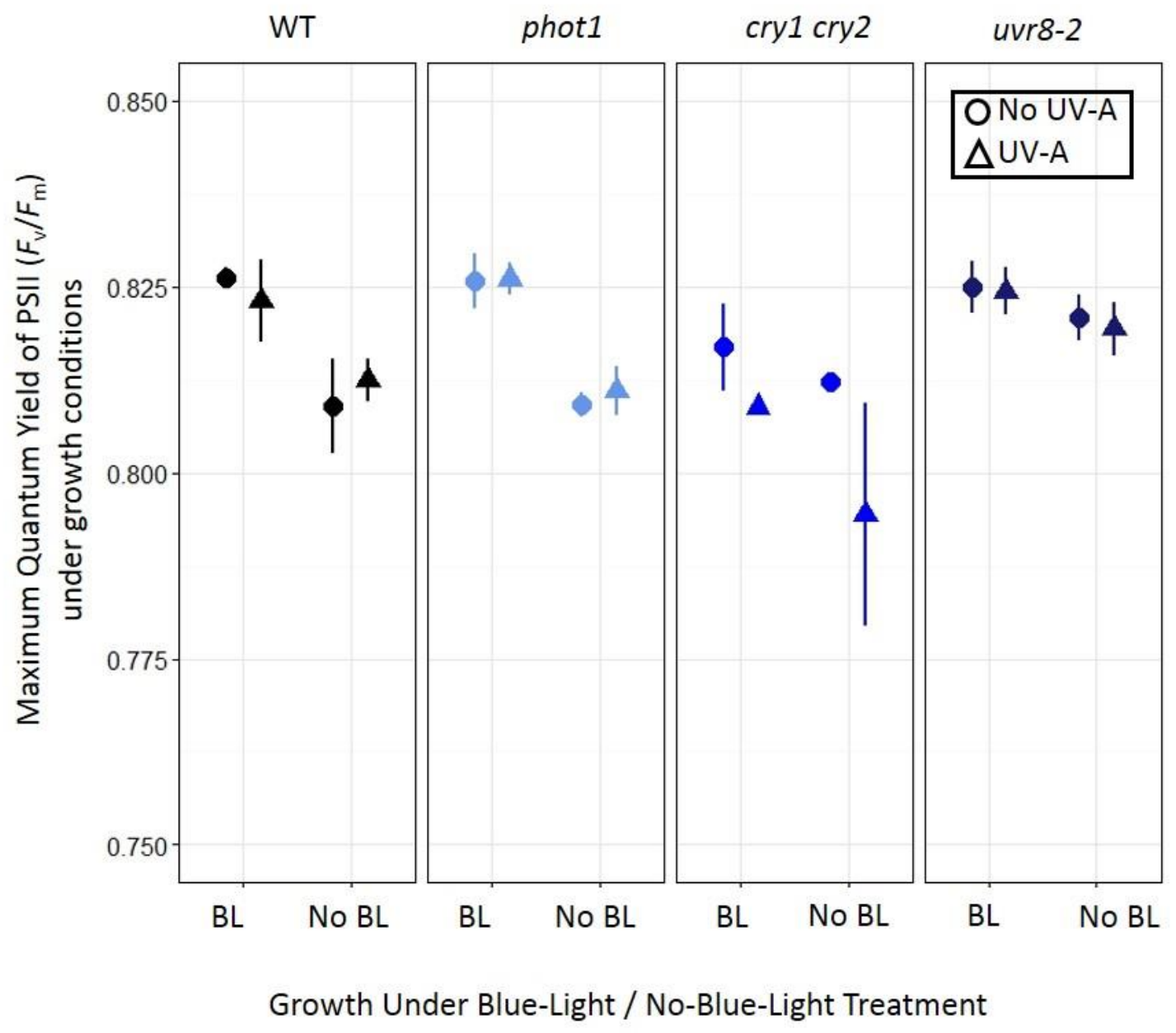

1062

1063 
1064 Fig. 5

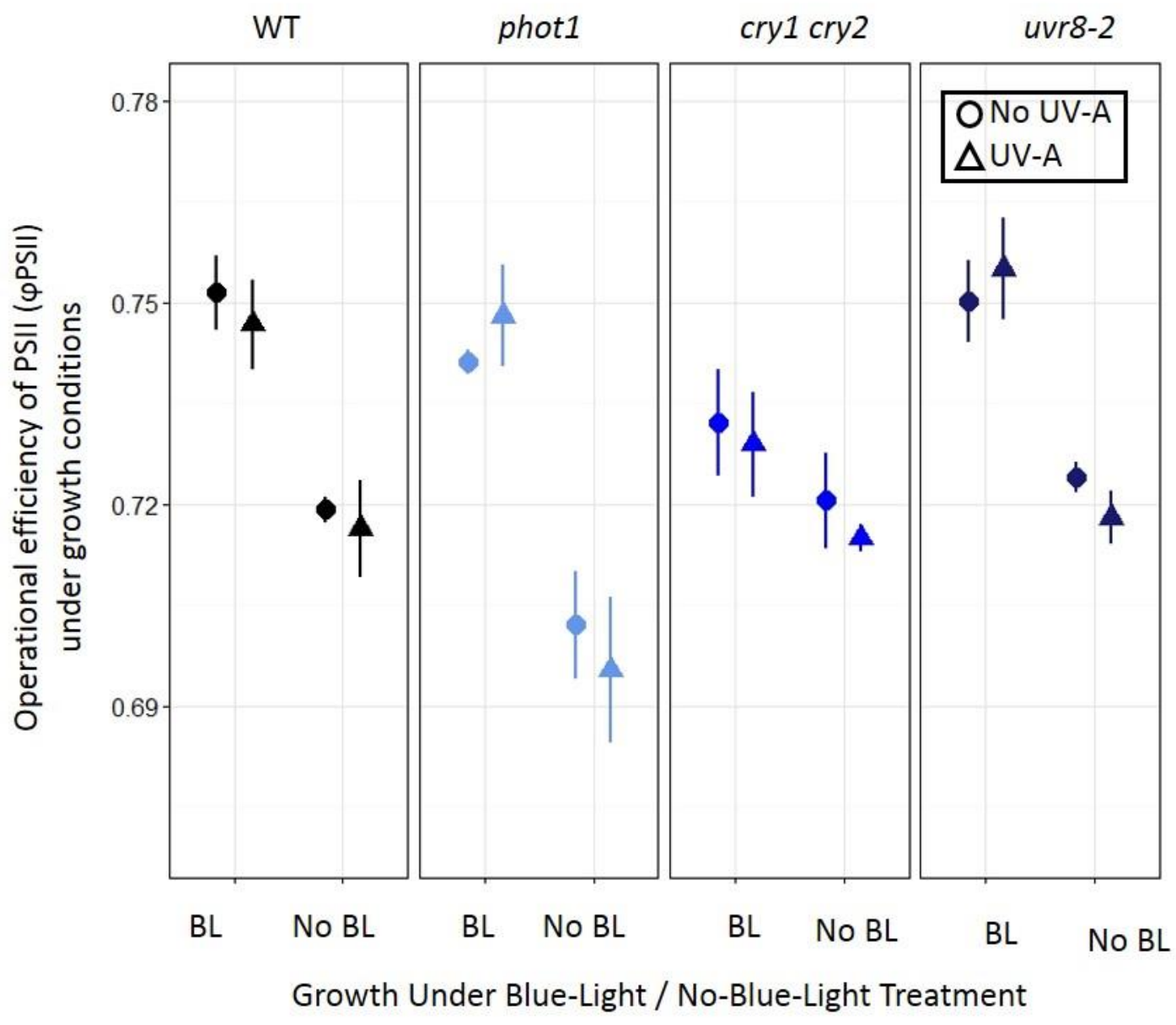

1066 
1067 Fig. 6

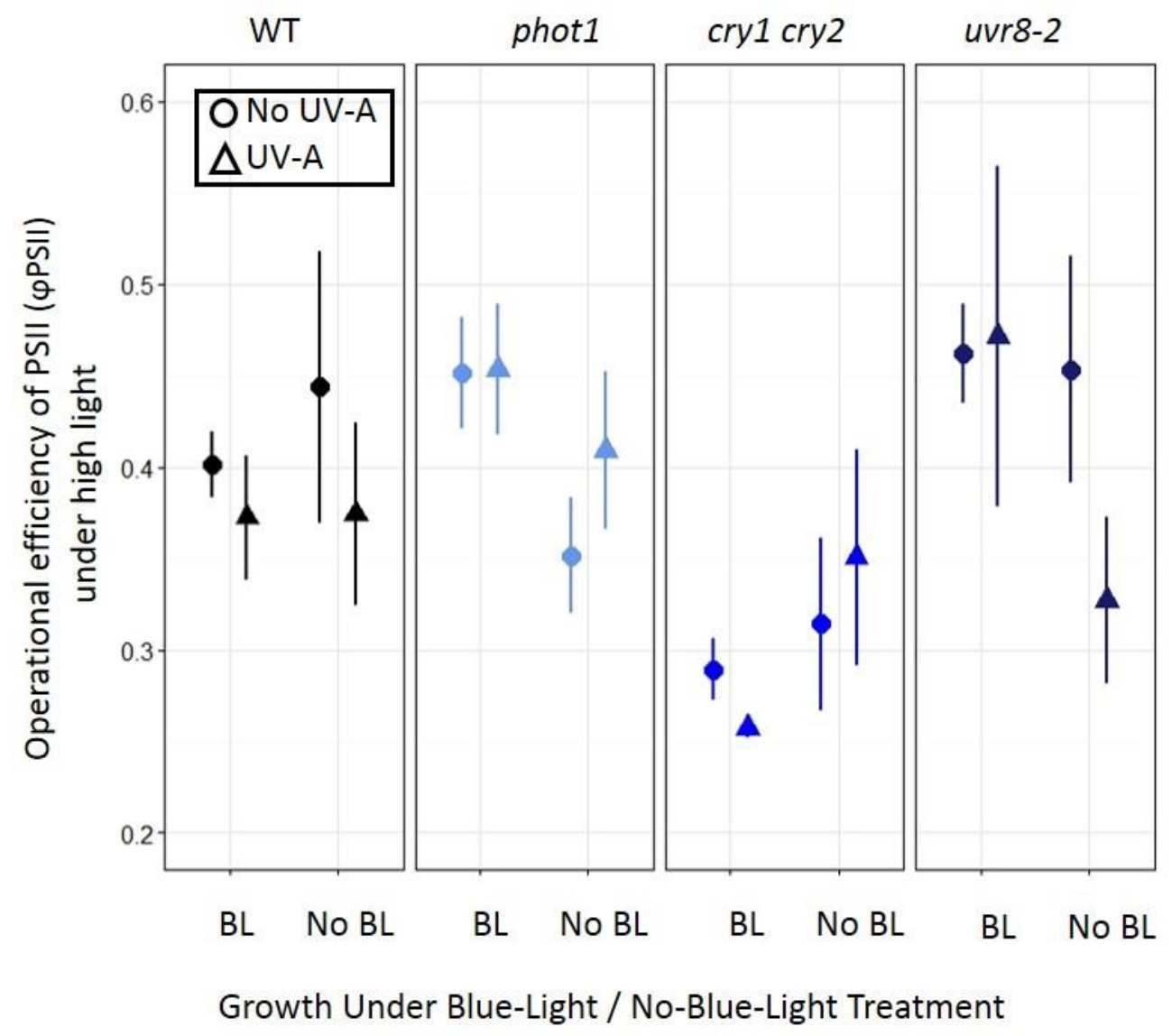

1068

1069 
$1070 \quad$ Fig. 7

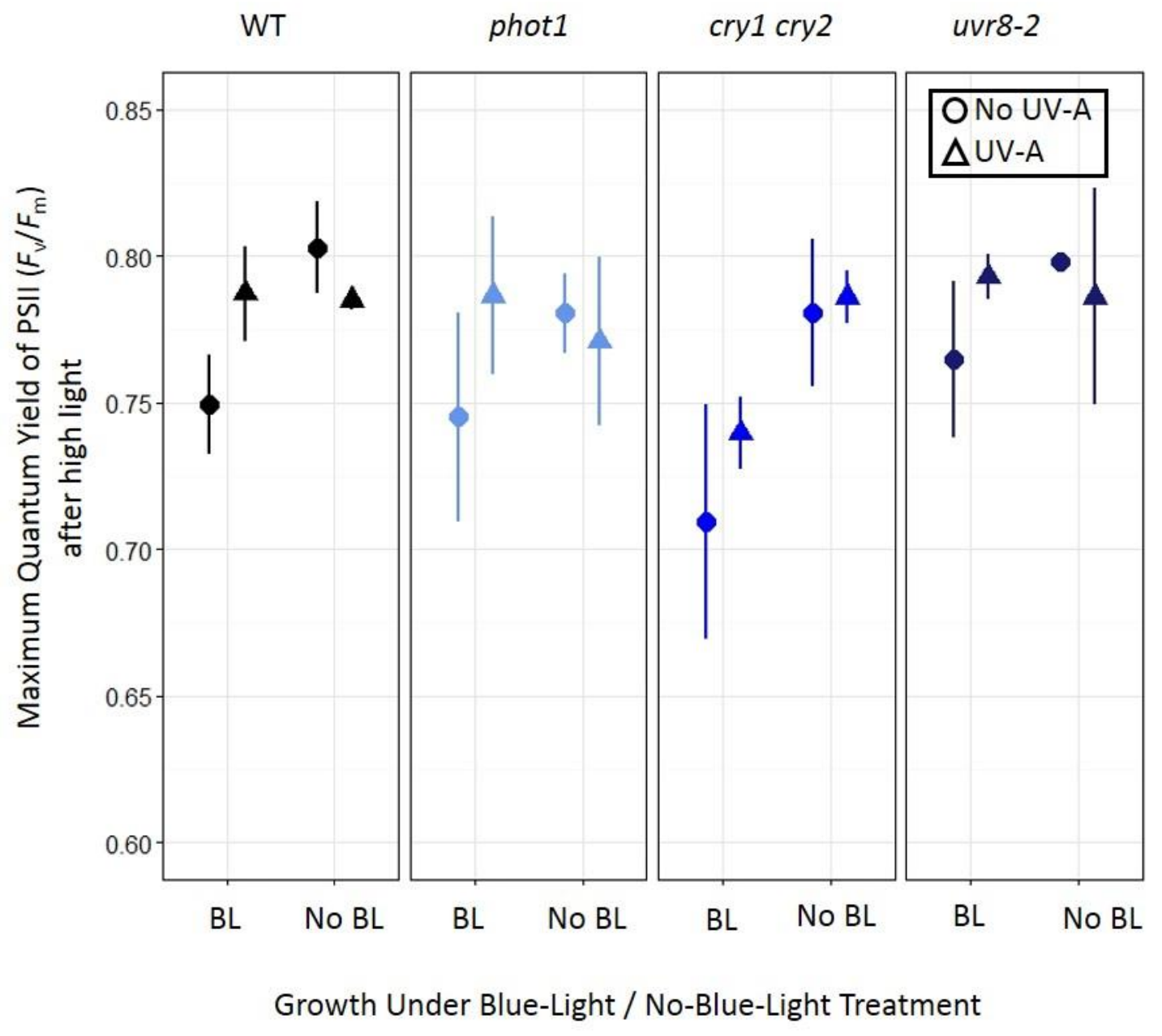

1071

1072 
$1073 \quad$ Fig. 8

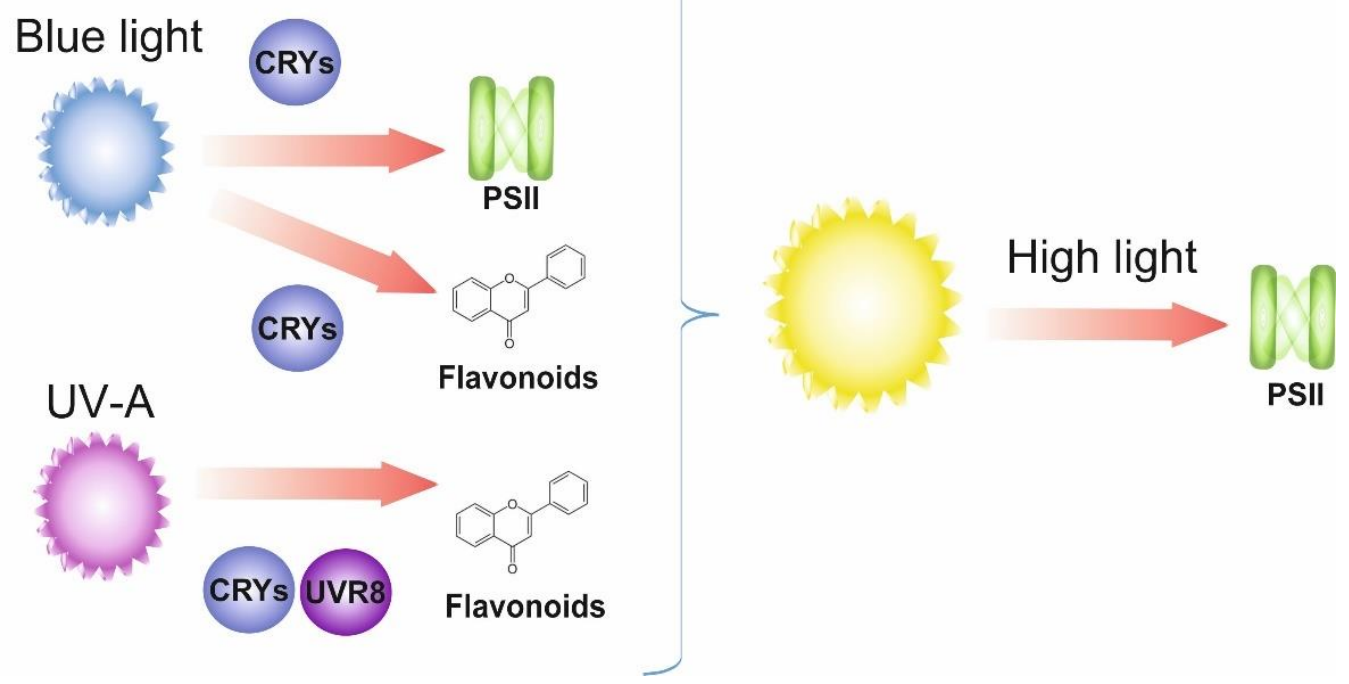

